\title{
Niveles de ingreso y desigualdad en Colombia: Un estudio econométrico por departamentos
}

\author{
Income and inequality levels in Colombia: An \\ econometric study by department
}

DOI: https://doi.org/10.17981/econcuc.41.1.2020.Econ.2

Artículo de revisión.

Fecha de recepción: 07/04/2019

Fecha de devolución: 22/10/2019

Fecha de aceptación: 30/10/2019

Fecha de publicación: 05/11/2019

\section{Roberto Mauricio Sánchez Torres}

Universidad Nacional de Colombia.

Bogotá, D.C. (Colombia)

rmsanchezt@gmail.com

\section{Luis Alejandro Ramírez Nariño \\ Universidad Nacional de Colombia. \\ Bogotá, D.C. (Colombia) \\ lramireznarino30@gmail.com}

\section{Luis Felipe Torres Méndez \\ Universidad Nacional de Colombia. \\ Bogotá, D.C. (Colombia) \\ luisf0019@gmail.com}

Para citar este artículo:

Sánchez, R., Ramírez, V. \& Torres, L. (2020). Niveles de ingreso y desigualdad en Colombia: Un estudio econométrico por departamentos. Económicas CUC, 41(1). 25-64. DOI: https://doi.org/10.17981/ econcuc.41.1.2020.Econ.2

\section{Resumen}

En esta investigación se tiene como propósito analizar conceptual y empíricamente el vínculo entre el crecimiento y la desigualdad del ingreso en Colombia a nivel departamental, destacándose las heterogeneidades económicas y los indicadores socioeconómicos que pueden estar articulados con esta relación. Se toma como referencia el promedio del ingreso per cápita familiar por departamento, y el coeficiente de Gini y el índice de Theil como indicadores de desigualdad. El estudio se realiza para el periodo 2002-2016, y se estiman diferentes metodologías econométricas buscando verificar la consistencia o inconsistencia de la relación y su robustez. En las estimaciones realizadas se evidenció que en Colombia a nivel departamental el vínculo entre crecimiento y desigualdad del ingreso no es claro, y los resultados varían dependiendo de la especificación del modelo y la metodología utilizada.

Palabras clave: Desigualdad; crecimiento económico; desarrollo económico; datos panel; Colombia

\section{Abstract}

The purpose of this paper is to analyze theoretically and empirically the link between growth and income inequality in Colombia by regions. Economic heterogeneities and socioeconomic indicators are considered in the inquiry of that relation. Per capita household income by department is considered as a reference of microeconomic welfare, Gini coefficient and Theil index are estimated as inequality indicators, the period from 2002 to 2016 is studied, and different econometric specifications are estimated to check consistency and robustness in the results. According with the estimations, the link between growth and income inequality in Colombia, at regional level, is not plain to understand because the results change depend on specification and methodology estimated.

Keywords: Inequality; economic growth; economic development; panel data; Colombia 


\section{INTRODUCCIÓN}

Uno de los principales problemas que ha venido afectando la calidad de vida de las personas en los diferentes países del mundo ha sido la desigualdad económica, que a su vez se ha articulado con concentración de la riqueza, falta de disponibilidad de bienes y servicios, bajos niveles de educación, falencias en la salubridad e inestabilidad financiera y política (Hernández y Chumaceiro, 2018; Zúñiga, 2017; Atkinson, 2015; Piketty, 2014; Stiglitz, 2012).

América Latina a lo largo del tiempo ha tenido de manera persistente elevados niveles de desigualdad del ingreso, ocasionados por factores como la composición geográfica y las heterogeneidades que hay en lo económico, político y social. En el caso colombiano, el crecimiento económico obtuvo una tasa promedio interanual de 4,19\% entre 2002 y 2016 , mientras que en los indicadores socioeconómicos se observó una importante disminución del analfabetismo y el desempleo, así como de los niveles de desigualdad del ingreso, no obstante, sigue siendo uno de los países con mayor disparidad en el mundo, explicada en una parte importante por las brechas existentes entre departamentos y regiones. Esa disparidad se ilustra en que los tres principales departamentos del país y la ciudad de Bogotá participan con más de la mitad del valor agregado nacional, mientras que hay departamentos con fuertes rezagos institucionales, sociales y económicos.

La discusión frente a la convergencia o divergencia en los procesos de crecimiento y desarrollo ha vuelto a ser parte central del debate académico de economía política sobre distribución del ingreso (Piketty, 2014). La relación entre los niveles de desarrollo y la desigualdad del ingreso ha sido objeto de amplia discusión y los estudios empíricos se han ampliado de manera sistemática desde el seminal artículo de Kuznets (1955), quien planteaba una relación de "U invertida": en fases iniciales de desarrollo hay un aumento de la desigualdad hasta un punto máximo a partir de la cual se presentan transferencias productivas a distintos sectores económicos y poblacionales, por lo que de forma espontánea en la consolidación del desarrollo habría una mejora distributiva, postulado conocido, siguiendo el enfoque clásico de Smith, como el "efecto derrame". Sin embargo, esa relación ha sido ampliamente discutida conceptual y empíricamente, por lo que no hay una regularidad en la forma en que se relaciona el nivel de desarrollo con la desigualdad del ingreso.

En esa temática se enmarca este artículo que busca estudiar el vínculo entre niveles de ingreso y su desigualdad en Colombia, considerando como unidad de análisis los departamentos de Colombia y aplicando técnicas econométricas para datos panel en el periodo 2002-2016. En otros estudios como los de Barón (2003), Bonilla (2011), Galvis y Meisel (2010) y Gaviria (2005), se ha revisado el tema aquí abordado para Colombia, pero para datos de corte transversal, series de tiempo, y estimando especificaciones con pocas variables de control, y aplicando métodos de estadística y econometría espacial. En este estudio se presenta nueva evidencia empírica de la relación entre niveles de ingreso y su desigualdad para el caso de Colombia, buscando confirmar o descartar la robustez de las 
estimaciones aplicando diferentes especificaciones, formas funcionales y métodos econométricos para datos panel; no sobra advertir que este tipo de análisis omite determinantes no observables y que se relacionan con la complejidad del fenómeno estudiado.

\section{Desarrollo}

\section{Crecimiento y desigualdad del ingreso}

Existen diversos estudios que explican la relación entre el crecimiento y la distribución del ingreso, considerando diferentes contextos políticos, sociales, y culturales. Para autores como Ray (2002), Piketty (2014) y Stiglitz (2012) no hay una relación clara entre el crecimiento económico y la desigualdad en el ingreso, debido a diferencias estructurales entre naciones o regiones y, por lo tanto, la mayoría de países no tienen la misma senda de crecimiento dado que tienen diferentes trayectorias en el incremento o disminución de la desigualdad.

Diversos análisis de la relación entre crecimiento y desigualdad del ingreso toman como referencia el estudio de Kuznets (1955) y nuevos planteamientos teóricos que surgen a partir de las críticas hacia su metodología para la medición de la desigualdad de las sociedades y su articulación con el crecimiento. Para Kuznets (1955), el vínculo entre crecimiento y desigualdad del ingreso se presenta mediante un proceso que se divide en tres etapas. En la etapa inicial, los países se encuentran en una situación denominada trampa de pobreza, es decir, bajos niveles de ingreso con reducida desigualdad y estructuras económicas tradicionales y de baja productividad; en la segunda etapa, los procesos de cambio técnico y mejoras productivas en sectores económicos estratégicos (industria) aumentan la desigualdad por la concentración de los beneficios resultantes de esas mejoras, alcanzando un punto de máxima desigualdad; y posteriormente, a partir de los avances productivos y la difusión intersectorial se presenta un aumento generalizado de ingresos, reduciendo la desigualdad de manera simultánea al crecimiento económico (Kuznets, 1955). Esta tendencia en la relación entre desigualdad y crecimiento del ingreso se ha conocido como la "U invertida" de Kuznets.

El planteamiento de Kuznets (1955) ha sido ampliamente cuestionado, y multiplicidad de autores han sugerido la importancia de matizar su validez, planteando nuevas perspectivas y visiones sobre este tema. En la literatura se encuentran autores como Casas (2017), Acemoglu \& Robinson (2012), Rodrik (2011) y Stiglitz (2012), quienes analizan el problema de la desigualdad como consecuencia de los aspectos políticos, las fallas del mercado y la globalización. Deininger \& Squire (1998) encuentran evidencia empírica que explica la relación entre la desigualdad y el crecimiento económico a través de los factores de producción y la distinción entre dominios geográficos. Recientemente, Piketty (2014) concluye que en las últimas décadas las fuerzas divergentes han generado aumentos de la desigualdad caracterizados por el mayor crecimiento de la tasa de rendimiento del capital que del producto y el ingreso. 
Existen diferentes dimensiones, variables, funcionamientos de la economía internacional y estrategias de política que inciden con multiplicidad de formas en el vínculo entre desigualdad y crecimiento del ingreso. Piketty (2014) y Stiglitz (2012) coinciden en que un auge económico no necesariamente proporciona una mejora en la calidad de vida de toda la población, debido a esto, analizan el avance que ha tenido la economía de mercado y cómo ha afectado en el aumento de la desigualdad. Asimismo, hacen referencia que los mercados no son estables, es decir, que presentan comportamientos dinámicos y perturbaciones durante el tiempo, dado que las economías presentan ciclos económicos. De igual forma, destacan algunas dimensiones como el ahorro y la inversión que se deben tener en cuenta en el análisis de la desigualdad.

Por su parte, Chumaceiro (2013) y Acemoglu \& Robinson (2012) plantean que para mejorar el crecimiento y desarrollo económico de un país se deben crear instituciones enfocadas en políticas inclusivas que permitan distribuir el poder gubernamental de manera eficiente y equitativa, de este modo, se podría incentivar una toma de decisiones direccionadas al beneficio colectivo y no al individual (elites extractivas). En relación con la desigualdad y los niveles de ingreso, los autores señalan que es imperativo garantizar normas institucionales que permitan que los individuos desarrollen sus capacidades y contribuyan con procesos de innovación, productividad y crecimiento económico.

De igual manera, Rodrik (2011) y Deininger \& Squire (1998) han observado como el crecimiento en las últimas décadas ha estado acompañado de mejoras significativas en indicadores sociales como el alfabetismo, la mortalidad infantil y la esperanza de vida. Sin embargo, a pesar de que algunos estudios sugieren la existencia de una relación inversa entre el crecimiento y la desigualdad, para muchos países la política macroeconómica de crecimiento y su dinámica productiva no conducen a mejoras en términos redistributivos (Rodrik, 2011).

A partir de lo anterior, se observa que la relación entre el crecimiento y la desigualdad del ingreso, contrastada con la hipótesis de Kuznets a nivel nacional e internacional, no es lineal ni se cumple la misma causalidad para los diferentes casos de estudio. Además, es importante incluir factores socioeconómicos e institucionales e implementar metodologías que presenten resultados más precisos y den una explicación a la problemática que se percibe en el mundo actual sobre este tema. Por último, se han encontrado diferentes aproximaciones metodológicas entre el crecimiento económico y la desigualdad del ingreso que serán abordados en la siguiente sección.

\section{Estudios empíricos de la relación entre crecimiento y desigualdad}

Una de las preocupaciones de los países en la última década radica en la búsqueda de mecanismos encaminados a reducir las brechas de desigualdad y, con ello, mejorar los niveles de calidad de vida de la población, la dinámica del ingreso y la reducción de la pobreza absoluta, siendo la desigualdad un aspecto donde 
se encuentra una relación directa o indirecta entre el desarrollo y crecimiento económico.

Los estudios empíricos que analizan la relación entre crecimiento y desigualdad del ingreso han tomado como referencia diferentes metodologías econométricas, sobre distintos estudios de caso, encontrando que esa relación no es monolítica ni se enmarca en un patrón para todos los países y/o regiones del mundo. Por ende, investigaciones recientes sobre este tema han implementado la técnica de datos panel que es la metodología utilizada en este trabajo, y sobre la que se hace énfasis en el resto del acápite.

Los trabajos de Bourguignon \& Morrison (1998) y Herzer \& Vollmer (2012) enfatizan que este tema del vínculo entre crecimiento y desigualdad generalmente presenta problemas de endogeneidad ${ }^{1}$, a partir de eso los autores aplican metodologías de Mínimos Cuadrados en 2 Etapas (MC2E) y pruebas de cointegración panel como soluciones para este inconveniente. En el caso de Bourguignon \& Morrison (1998) su investigación se realiza para 38 países durante el periodo 1960-1970 utilizando estimaciones econométricas con datos panel (efectos fijos y aleatorios), en el que incorporan dos variables instrumentales: la primera consiste en una diferencial entre los ingresos rurales y urbanos; y la segunda, trata de una dummy de la productividad laboral sectorial, con el fin de que el modelo no presente causalidad entre las variables de estudio, encontrando que la reducción de los niveles de desigualdad y la pobreza se debe a los incrementos en la productividad del sector primario y el acceso a la educación (Bourguignon \& Morrison, 1998).

En el estudio de Herzer \& Vollmer (2012) se analiza una muestra de 46 países democráticos y no democráticos ${ }^{2}$ y utilizan la metodología de efectos fijos, adicionalmente realizan un test de cointegración panel para corregir la estacionalidad de la inversión y el ingreso per cápita en el que buscan observar los efectos a largo plazo de la desigualdad del ingreso durante el periodo 1970-1995, obteniendo como resultado que los países no presentan cambios significativos en términos de disparidad y que la relación desigualdad-crecimiento es negativa al largo plazo, además, no hay diferencias importantes entre países ricos y pobres o entre países democráticos y no democráticos (Herzer \& Vollmer, 2012).

Asimismo, Argüello (2006) y Bourguignon, Ferreira \& Menéndez (2007) hacen un análisis empírico de las principales debilidades y limitantes que se presentan en la medición del crecimiento económico y la desigualdad del ingreso, en el que implementan una metodología de datos panel. Argüello (2006) utiliza una muestra de 52 países y 225 observaciones para el periodo 1960-1995 realizando las técnicas de efectos fijos y aleatorios, encontrando que no hay una relación clara entre el crecimiento económico y la desigualdad. Igualmente, Bourguignon et al. (2007) toman como caso de estudio 18 países latinoameri-

\footnotetext{
1 La endogeneidad se presenta cuando la $\operatorname{Cov}(x, u)$ es diferente a 0 , y se ocasiona por omisión de variables, simultaneidad, errores de medición, entre otras.

2 De acuerdo con los autores un país se clasifica como no democrático si el puntaje de democracia de Polity es inferior a 6 durante más del 75\% del tiempo entre 1970 y 1995.
} 
canos, concluyendo que no hay una relación de "U invertida", debido a las heterogeneidades causadas por las diferentes características que tiene cada nación (Bourguignon et al., 2007).

En cuanto a las indagaciones que se han realizado acerca de la relación entre el crecimiento económico y la desigualdad del ingreso entre espacios geográficos de un mismo país se destacan investigaciones como las de Gallo, Garrido, Gonzáles y Pozo (2015), Azzoni (2001) y Bourguignon et al. (2007). En el texto de Gallo et al. (2015) se analiza la divergencia territorial ${ }^{3}$ de Perú a nivel departamental a través de algunos indicadores socioeconómicos, tales como: el coeficiente de Gini, la tasa de pobreza, el PIB per cápita urbano y rural, entre otros (p. 9). Los autores encuentran que en Perú existe una divergencia regional, explicado en parte por las desigualdades geográficas, y el rezago de varias regiones del país y la falta de articulación económica con los centros de concentración económica. No obstante, los resultados obtenidos en las estimaciones no presentaron robustez debido a la limitación que hubo en la recopilación de los datos (Gallo et al., 2015).

Por otro lado, Azzoni (2001) y Bourguignon et al. (2007) observan la dinámica de la disparidad del ingreso de Brasil a partir de indicadores convencionales para la medición de la desigualdad. En efecto, Azzoni (2001) realiza una prueba de convergencia Beta para ubicar en qué parte están las regiones ricas y pobres en la curva de Kuznets, encontrando que las regiones del sur y sureste presentan mayores ingresos per cápita y una mejor distribución del mismo, en contraste, las zonas del norte, noreste y centro-oeste que tienden a incrementar sus niveles de desigualdad en el trascurso del tiempo. Por último, concluye que hay una relación de "U invertida" entre crecimiento y desigualdad en las regiones de Brasil (p. 135). Mientras Bourguignon et al. (2007) identifica que la variable lugar de nacimiento está relacionada con la desigualdad de oportunidades ${ }^{4}$, pues hay diferencias entre las regiones Norte-Noroeste y Centro-Oeste que tienen un efecto negativo con respecto a la región Sur-Suroeste.

En el caso de Colombia, se encuentran otros estudios que tratan de explicar con diferentes especificaciones econométricas, unidades de observación y periodos de tiempo, la relación entre crecimiento y desigualdad del ingreso. En primer lugar, Gaviria (2005) aborda su investigación mediante una metodología de corte transversal a partir de variables socioeconómicas como: el coeficiente de Gini, la infraestructura, los niveles de industrialización, el capital humano y la convergencia del PIB per cápita, encontrando que existe cierto tipo de vínculo entre el crecimiento y la distribución del ingreso, debido a que los parámetros presentan el signo esperado y se observa una relación inversa entre el crecimiento económico y las variables de desigualdad (Gaviria, 2005).

\footnotetext{
3 El autor implementa una metodología de causalidad de Granger que permite identificar si existe o no una correlación entre variables, para este caso el PIB rural y PIB urbano (Gallo et al., 2015).

4 El índice de desigualdad de oportunidades consiste en segmentar los factores que son asignados aleatoriamente al individuo y que pueden influir en su ingreso, tales como: el sexo, la raza, el lugar de nacimiento, la riqueza, la educación, entre otros (Bourguignon et al., 2007).
} 
Por su parte, Barón (2003) aborda el tema de la disparidad del ingreso a partir de la metodología de convergencia tipo beta y sigma, con el objetivo de observar la evolución de la desigualdad en el periodo 1980-2000 a nivel nacional. De acuerdo con el autor, las condiciones de pobreza e ingresos per cápita no se distribuyen de manera homogénea en el territorio colombiano, es decir, hay una alta concentración del ingreso en las principales ciudades del país (Barón, 2003).

De igual forma, Galvis y Meisel (2010) buscan contrastar los niveles de desigualdad y pobreza a nivel regional, enfocando su análisis en el coeficiente de Gini, el ingreso per cápita de los hogares y el de los ocupados, además, implementan una metodología de perspectiva espacial ${ }^{5}$. De acuerdo con el estudio, la periferia colombiana, comprendida por la Costa Caribe, Costa Pacífica, Orinoquia y Amazonia, presentan bajos niveles de crecimiento económico, evidentes concentraciones de desigualdad y una incidencia en la pobreza considerable (Galvis y Meisel, 2010). Además, Galvis y Meisel (2010) utilizan una metodología similar a la de Bonilla (2011), encontrando que en las ciudades y regiones la relación que hay entre el crecimiento económico y la disparidad del ingreso presenta una forma de U, distinta a la relación planteada por Kuznets (1955).

Bonilla (2011) enfoca su estudio en la medición de la desigualdad en espacios interregionales e intrarregionales por medio de los indicadores de Gini y Theil realizando correlaciones de Spearman, distintas medidas de ingresos y gastos, y desigualdad intergrupal, asimismo, la muestra de estudio incluye las regiones y ciudades principales y las áreas urbanas y rurales. En esta indagación se concluye que en Colombia se observan diferencias en la desigualdad del ingreso, dado que la composición de los departamentos y ciudades del país presentan diferentes heterogeneidades en términos estructurales, y no solamente en la disparidad del ingreso. Desde una perspectiva similar y a través de metodologías de descomposición, en el estudio de Sánchez (2017) se plantea que hay una persistencia en las brechas de ingreso entre regiones y departamentos del país que explican en una porción importante la desigualdad, aspecto que se hace más preocupante cuando se observa que algunos de los departamentos con mayor desigualdad del ingreso también sufren los mayores niveles de pobreza y bajos niveles de vida.

Con base en la revisión de la literatura mencionada en esta sección, se observa que el proceso habitualmente abordado para la explicación de la relación entre la desigualdad, el crecimiento y el desarrollo económico, se ha realizado a partir de técnicas como efectos fijos y aleatorios para datos panel, pruebas de convergencia Beta, correlaciones de Spearman y el índice I de Moran. Además, es necesario incluir variables que capten dimensiones institucionales, educativas, de comercio exterior, progreso técnico, entre otras, en contraste con estudios unidimensionales que relacionan los niveles de ingreso con los de desigualdad. Por último, en los estudios encontrados se evidencia que no existe una relación clara entre crecimiento económico y desigualdad del ingreso, debido a que la desigualdad no se puede explicar únicamente por disparidades en el ingreso, ya que es un tema que contempla múltiples y diversos factores.

5 Utilizan el índice I de Moran que consiste en cuantificar el grado de auto-correlación entre las variables de estudio. 


\section{MetodoloGía}

\section{Fuente de información}

Los datos utilizados en esta investigación provienen del Departamento Administrativo Nacional de Estadísticas de Colombia (DANE) a partir de la Encuesta Continua de Hogares (ECH) y la Gran Encuesta Integrada de Hogares (GEIH) (DANE, 2017a), que captura gran parte de la información de las familias colombianas, y es la fuente con la que se estiman los indicadores socioeconómicos; además, algunas de las variables provienen de información provista del Departamento Nacional de Planeación (DNP, 2017) y de las Cuentas Nacionales, precios e indicadores de niveles de vida del DANE (DANE, 2017b).

Con los modelos indagados en este estudio se busca analizar la relación entre los niveles de ingreso y su desigualdad a partir de metodologías econométricas que se presentan en el siguiente acápite. Una de las consideraciones que hay que tener en cuenta en esta investigación es como la determinación de los niveles de desigualdad se explican por diferentes dimensiones del bienestar, y características socioeconómicas y productivas que pueden estar vinculadas con los niveles de ingreso. En la Tabla 1 se presentan las variables que se considerarán en este estudio descriptivo y econométrico, se ilustra la definición, la abreviación y la fuente de información.

TABLA 1.

Definición de variables socioeconómicas

\begin{tabular}{|c|c|c|c|c|}
\hline & Variable & Abreviación & Definición & Fuente \\
\hline \multirow{9}{*}{ Económicos } & $\begin{array}{l}\text { Logaritmo natural del promedio del ingreso } \\
\text { per cápita familiar por departamento }\end{array}$ & LN(IPCFD) & $\frac{\sum_{i=1}^{n} \text { Ingreso per cápita familiar }}{\text { Población total }}$ & $\begin{array}{l}\text { ECH Y GEIH } \\
\text { (DANE) }\end{array}$ \\
\hline & Participación sector agrícola & PA & $\frac{\text { Valor agregado agricultura }}{\text { Valor agregado departamental }} \times 100$ & \multirow{6}{*}{$\begin{array}{l}\text { Cuentas } \\
\text { nacionales } \\
\text { (DANE) }\end{array}$} \\
\hline & Participación sector industria manufacturera & PIM & $\frac{\text { Valor agregado industria manufacturera }}{\text { Valor agregado departamental }} \times 100$ & \\
\hline & Participación sector minas y canteras & $\mathrm{PM}$ & $\frac{\text { Valor agregado minas } y \text { canteras }}{\text { Valor agregado departamental }} \times 100$ & \\
\hline & Participación sector construcción & PCONST & $\frac{\text { Valor agregado construcción }}{\text { Valor agregado departamental }} \times 100$ & \\
\hline & Participación sector comercio & PCRH & $\frac{\text { Valor agregado comercio }}{\text { Valor agregado departamental }} \times 100$ & \\
\hline & Participación servicios & PSERV & $\frac{\text { Valor agregado servicios }}{\text { Valor agregado departamental }} \times 100$ & \\
\hline & Logaritmo natural de la inversión & LN(INV) & Niveles de inversión por departamento & DNP \\
\hline & Coeficiente de apertura & $\mathrm{CA}$ & $\frac{\text { Exportaciones }+ \text { Importaciones }}{\text { Valor agregado departamental }} \times 100$ & $\begin{array}{c}\text { Comercio } \\
\text { exterior } \\
\text { (DANE-DIAN) }\end{array}$ \\
\hline \multirow{3}{*}{ Educativos } & Asistencia a educación básica & AEB & $\frac{\text { Personas entre } 5-16 \text { años que } A E B}{\text { Total de personas entre } 5-16 \text { años }} \times 100$ & \multirow{8}{*}{$\begin{array}{l}\text { ECH Y GEIH } \\
\text { (DANE) }\end{array}$} \\
\hline & Asistencia a educación superior & AES & $\frac{\text { Personas entre } 17-26 \text { años que AES }}{\text { Total de personas entre } 17-26} \times 100$ & \\
\hline & Personas con educación superior & PCES & $\frac{\text { PCES mayores a } 26 \text { años }}{\text { Total de personas mayores a } 26 \text { años }} \times 100$ & \\
\hline \multirow{2}{*}{ Demográficos } & Población urbana & $\mathrm{PU}$ & $\frac{\text { Población total urbana }}{\text { Población total }} \times 100$ & \\
\hline & Edad promedio & EP & $\frac{\sum_{i=1}^{n} \text { Edad }}{\text { Población total }} \times 100$ & \\
\hline Salud & Personas que cotizan a salud & PCS & $\frac{\text { PCS }}{\text { Población total }} \times 100$ & \\
\hline \multirow{2}{*}{ Laborales } & Tasa de ocupados & TO & $\frac{N^{\circ} \text { de ocupados }}{\text { Población en edad de trabajar }} \times 100$ & \\
\hline & Tasa de desempleo & TD & $\frac{N^{\circ} \text { de desempleados }}{\text { Población económicamente activa }} \times 100$ & \\
\hline
\end{tabular}

Fuente: Elaboración propia. 


\section{Metodología econométrica}

La metodología que se implementa en esta investigación es de tipo cuantitativo no experimental a través de un estudio empírico con datos panel que consiste en recopilar información de una muestra de $(\mathrm{N})$ observaciones (departamentos) en diferentes periodos de tiempo (T) (2002-2005 y 2008-2016), con el fin de analizar el vínculo entre los niveles de ingreso y su desigualdad.

La variable de análisis será el promedio del Ingreso Per Cápita Familiar por Departamento [IPCFD], sobre ella se computarán los indicadores de desigualdad en cada departamento y el nivel medio de ingreso. Los indicadores de desigualdad utilizados en este trabajo son el coeficiente de Gini y el índice de Theil, que son medidas utilizadas principalmente por la consistencia en sus propiedades ${ }^{6}$ (Cowell, 2011). El cómputo del Coeficiente de Gini (1) y el Índice de Theil (2) para los microdatos utilizados es:

$$
\begin{gathered}
\text { Gini }=\frac{1}{2 n^{2} \bar{y}} \sum_{i=1}^{n} \sum_{j=1}^{n}\left|y_{i}-y_{j}\right| \\
\text { Theil }=\frac{1}{n} \sum_{i=1}^{n} \frac{y_{i}}{\bar{y}} \log \left(\frac{y_{i}}{\bar{y}}\right)
\end{gathered}
$$

En donde $i$ son los individuos, n es el tamaño de la población, el ingreso de cada $i$, y es el ingreso medio, $\left|y_{i}-y_{j}\right|$ significa la brecha de ingresos que tiene cada individuo $\left(y_{i}\right)$ en relación al resto de la población $\left(y_{j}\right)$.

En este estudio se realizarán estimaciones econométricas de Mínimos Cuadrados Ordinarios (MCO) para datos de corte transversal, primera diferencia, y estimaciones de efectos fijos y aleatorios para datos panel en los periodos 2002-2005 y 20082016. Las variables explicadas son el Coeficiente de Gini y el Índice de Theil y las variables explicativas son: El promedio del logaritmo natural del ingreso per cápita familiar por departamento y las que se mencionan en la Tabla 1.

En primera instancia se estima un modelo preliminar que relaciona el coeficiente de Gini $^{7}$ y el $L N(I P C F D)$, mediante una Regresión Lineal Simple (RLS) que se expresa en la ecuación (3), considerando los datos como corte transversal por medio de MCO:

$$
\operatorname{GINI}_{i}=\beta_{0}+\beta_{1} L N\left(\operatorname{IPCFD}_{i}\right)+\mu_{i}
$$

Luego, se incluye una relación cuadrática (RLS2) representada en la ecuación (4), estimada por MCO:

\footnotetext{
${ }^{6}$ Las propiedades básicas de los indicadores de desigualdad son: Anonimato, principio de transferencia, homogeneidad en los ingresos y en la población.

7 También se hicieron todas las estimaciones considerando como indicador de desigualdad el índice de Theil.
} 


$$
\operatorname{GINI}_{i}=\beta_{0}+\beta_{1} L N\left(I P C F D_{i}\right)+\beta_{2} L N\left(I P C F D_{i}\right)^{2}+\mu_{i}
$$

Después, se incorporó una variable dummy años ( $\left.D i^{\prime}\right)$ en las ecuaciones (3) y (4), que muestra los posibles cambios de las variables de un año a otro, además, en las ecuaciones (5) a (8) se incluyeron las variables de control $\left(X_{i}^{\prime}\right)$, utilizando las mismas especificaciones y metodologías de las ecuaciones anteriormente mencionadas.

$$
\begin{aligned}
& \operatorname{GINI}_{i}=\beta_{0}+\beta_{1} \operatorname{LN}\left(\operatorname{IPCFD}_{i}\right)+\beta_{k} X_{i}^{\prime}+\mu_{i} \\
& \operatorname{GINI}_{i}=\beta_{0}+\beta_{1} L N\left(\operatorname{IPCFD}_{i}\right)+\beta_{2} L N\left(\operatorname{IPCFD}_{i}\right)^{2}+\beta_{k} X_{i}{ }_{i}+\mu_{i} \\
& \operatorname{GINI}_{i}=\beta_{0}+\beta_{1} L N\left(\operatorname{IPCFD}_{i}\right)+\beta_{k} X^{\prime}{ }_{i}+\beta_{k} D_{i}^{\prime}+\mu_{i} \\
& \operatorname{GINI}_{i}=\beta_{0}+\beta_{1} L N\left(I P C F D_{i}\right)+\beta_{2} L N\left(I P C F D_{i}\right)^{2} \\
& +\beta_{k} X^{\prime}{ }_{i}+\beta_{k} D^{\prime}{ }_{i}+\mu_{i}
\end{aligned}
$$

En donde el vector $X_{i}^{\prime}$ incluye las covariables adicionales a los niveles de ingreso que se consideran en dos especificaciones estimadas: la primera, incluye las variables PIM, CA, PCES, PU y TD; y la segunda, incorporará todas las variables ilustradas en la Tabla 1 exceptuando $\mathrm{PIM}^{8}$.

Posteriormente, se hace una estimación de Mínimos Cuadrados Ordinarios (MCO) para la metodología de primera diferencia ${ }^{9}$, que es una primera aproximación a la técnica de efectos fijos para datos panel. La ecuación de primera diferencia viene dada ${ }^{10}$

$$
\begin{aligned}
\Delta G I N I_{i}=\beta_{0}+\beta_{1} \Delta L N\left(\operatorname{IPCFD}_{i}\right) & +\beta_{2} \Delta L N\left(I P C F D_{i}\right)^{2} \\
& +\beta_{k} \Delta D^{\prime}{ }_{i}+\beta_{k} \Delta X^{\prime}{ }_{i}+\Delta \mu_{i}
\end{aligned}
$$

La variación $(\Delta)$ muestra la diferencia de las variables entre los periodos analiza$\operatorname{dos}\left(t_{n}-t_{n-1}\right)$.

\footnotetext{
8 Se excluye PIM porque se toma como grupo de referencia en las variables binarias sectoriales.

9 La estimación en primera diferencia consiste en diferenciar el efecto inobservable que permanece constante en los diferentes periodos de corte transversal.

${ }^{10}$ La estimación de primera diferencia se realiza para todas las especificaciones presentadas en las ecuaciones (3) a (8).
} 
Por último, se estiman dos metodologías para datos panel en dos periodos de tiempo (2002-2005 y 2008-2016). La metodología de datos panel es importante porque resuelve la heterogeneidad no observada en los diferentes periodos $(T=1,2,3 \ldots N)$ y es una alternativa para los estudios de economía aplicada dependiendo del tipo de datos a utilizar. En primer lugar, se plantea la ecuación (10) que describe la forma funcional de la técnica de efectos fijos para datos panel, considerando heterogeneidad no observada ${ }^{11}\left(Z_{i}\right)$ del modelo.

$$
\begin{aligned}
\operatorname{GINI}_{t}=\beta_{0}+\beta_{1} L N\left(\text { IPCFD }_{t}\right) & +\beta_{2} L N\left(I P C F D_{t}\right)^{2} \\
& +\beta_{k} X^{\prime}{ }_{t}+Z_{i}+\mu_{t}
\end{aligned}
$$

Asimismo, si se observa que existe heterogeneidad no observada en la estimación se puede ajustar mediante dos formas: la primera, corrige el efecto individual de las variables $\left(Z_{i}\right)$ y la segunda, es transformar la variable para que no presente correlación y no sesgue el modelo (Greene, 2003). De esta manera, se puede corregir los posibles sesgos por omisión de variables al utilizar datos de corte transversal, esto para variables que no cambian significativamente en el tiempo y así evitar problemas de endogeneidad ${ }^{12}$.

A partir de lo anterior, se considera la heterogeneidad no observada $\left(Z_{i}\right)$ como un término constante que no cambia con el tiempo y no es estocástico (Greene, 2003). Para ello, se utilizan los estimadores intragrupal (within), que de acuerdo con Wooldridge (2013) estos procedimientos "utilizan la variación en el tiempo en $y$ y $x$ dentro (within) de cada observación de corte transversal” (p. 485). Basado en lo anterior, se obtiene la siguiente ecuación (11) que se estima a través de MCO:

$$
\begin{aligned}
\operatorname{GINI}_{i t}-\overline{\operatorname{GINI}_{\iota}} & =\beta_{1}\left(\operatorname{LN}\left(\operatorname{IPCFD} D_{i t}\right)-\overline{\left.\operatorname{LN(IPCFD_{l})}\right)}\right. \\
& +\beta_{2}\left(\operatorname{LN}\left(I P C F D_{i t}\right)^{2}-\overline{\operatorname{LN}\left(I P C F D_{l}\right)^{2}}\right) \\
& +\beta_{k}\left(X^{\prime}{ }_{i t}-\overline{X^{\prime}}{ }_{l}\right)+\mu_{j t}-\overline{\mu_{\jmath}}
\end{aligned}
$$

Finalmente, la ecuación (12) muestra la técnica de efectos fijos:

$$
\begin{aligned}
\widetilde{G I N} I_{i t}=\beta_{1}\left(L N\left(\widetilde{I P C F} D_{l t-1}\right)\right) & +\beta_{2}\left(L N\left(\widetilde{P C F} D_{l t}\right)^{2}\right) \\
& +\beta_{k}\left(\widetilde{X^{\prime}}{ }_{l t}\right)+\widetilde{\mu_{j}}
\end{aligned}
$$

Por otro lado, la segunda estimación econométrica con datos panel es la de efectos aleatorios que tiene la misma dinámica y supuestos que la de efectos fijos,

\footnotetext{
${ }^{11}$ (Zi) incluye las variables observables y no observables como: los aspectos idiosincráticos, la corrupción, las características geográficas, los recursos naturales, la cultura, las estructuras económicas y sociales formadas por trayectorias históricas.

${ }^{12}$ En el caso de variables omitidas que cambian en el tiempo, el problema de endogeneidad persistiría. Autores como Bourguignon \& Morrison (1998) y Herzer \& Vollmer (2012) corrigen este error a través de variables instrumentales y test de cointegración panel.
} 
exceptuando que para los efectos aleatorios las variables inobservables $\left(Z_{i}\right)$ no pueden estar correlacionadas con las variables independientes del modelo en ningún momento del periodo $(T=1,2,3 \ldots N)$, debido a que en la técnica de efectos fijos los parámetros $(\beta k)$ no son del todo consistentes e ignora la correlación que hay entre las perturbaciones $\left(\mu_{j t}\right)$ con las variables inobservables, lo contrario pasa con los efectos aleatorios en donde el método que utiliza es el de Mínimos Cuadrados Generalizados (MCG).

En primer lugar, se plantea la ecuación (13) de no correlación con las variables explicativas:

$$
\operatorname{Cov}\left(X_{i t}^{\prime}, Z_{i}\right)=0, T=1,2, \ldots, t
$$

Luego, se especifica el nuevo término de error en la ecuación (14):

$$
\begin{aligned}
\operatorname{GINI}_{i t}=\beta_{0}+\beta_{1} L N\left(I P C F D_{i t}\right) & +\beta_{2} L N\left(I P C F D_{i t}\right)^{2} \\
& +\beta_{k} X^{\prime}{ }_{i t}+V_{t}
\end{aligned}
$$

En donde $V_{t}=Z_{i}+\mu_{i t}$, debe cumplir el supuesto de media condicional cero $\left(E\left[V_{t} / X_{t}^{\prime}\right.\right.$, $\left.L N\left(I P C F D_{t}\right), L N\left(I P C F D_{t}\right)^{2}\right]=0$. Finalmente, la ecuación (15) es la estimación de la técnica de efectos aleatorios:

$$
\begin{aligned}
G_{I N I_{i t}-\alpha \overline{G I N I_{l}}}=\beta_{0}(1-\alpha)+\beta_{1}\left(L N\left(I P C F D_{i t}\right)\right. \\
\left.\left.-\alpha \overline{L N\left(I P C F D_{l}\right.}\right)\right)+\beta_{2}\left(L N\left(I P C F D_{i t}\right)^{2}\right. \\
\left.-\alpha \overline{L N\left(I P C F D_{l t}\right)^{2}}\right)+\beta_{k}\left(X_{i t}^{\prime}-\alpha \overline{X_{i}^{\prime}}\right)+\left(V_{j t}-\alpha \overline{V_{j}}\right)
\end{aligned}
$$

En donde $a=1-\left[\sigma_{u}^{2} /\left(\sigma_{u}^{2}+T \sigma_{z}^{2}\right)\right] \frac{1 / 2}{2}$

Una última especificación para los modelos de efectos aleatorios y efectos fijos fue la inclusión de una variable de interacción entre el nivel de ingreso y los años respectivos. Lo anterior para verificar que aunque el coeficiente estimado de los modelos podría no ser significativo, se establece si el efecto del cambio en el ingreso en los años considerados sobre la desigualdad fue significativo y la dirección que presentó.

Una vez se estiman los modelos de efectos fijos y aleatorios es necesario realizar el test de Hausman (1978), con el fin de verificar cuál de las dos técnicas se ajusta más para el caso de estudio. En particular, el objetivo es verificar si los inobservables (o efectos fijos ) están o no correlacionados con las variables explicativas, ya que de esto depende el mejor ajuste del modelo, en caso de que no exista esa correlación, la estimación de efectos aleatorios (15) es más eficiente. De acuerdo con Hausman (1978), su estadístico de especificación se distribuye Chi-Cuadrado y su cómputo es: 


$$
H=\left(\beta_{c}-\beta_{e}\right)^{\prime}\left(V_{c}-V_{e}\right)^{-1}\left(\beta_{c}-\beta_{e}\right)
$$

Donde $\beta_{c}$ es el vector de coeficientes del estimador consistente (efectos fijos), $\beta_{e}$ es el vector de coeficientes del estimador eficiente (efectos aleatorios), y $V_{c}$ y $V_{e}$ es la matriz de varianzas y covarianzas de los estimadores consistentes y eficientes, respectivamente. La hipótesis nula del test es que los coeficientes por el método de efectos fijos son consistentes y los de efectos aleatorios son eficientes (por tanto, no habría diferencia estadísticamente significativa en los coeficientes de ambas estimaciones, y se estaría inclinado a considerar las estimaciones de efectos aleatorios por su mayor eficiencia), contra la alternativa que indica que los coeficientes de efectos fijos es consistente y el de efectos aleatorios es inconsistente. Por lo tanto, si se rechaza la hipótesis nula habría correlación de los inobservables con las variables explicativas y se preferiría la estimación consistente por efectos fijos.

Las estimaciones se realizarán considerando ambos indicadores de desigualdad (1) y (2) como variables dependientes; dos formas funcionales del LN(IPCFD) (una lineal y una lineal y cuadrática) como explicativas; y dos conjuntos de variables de control: una sintética en la que se incluyen PIM, CA, PCES, PU, TD; y otra versión ampliada en la que se incluyen todas las variables presentadas en la Tabla 1, este modelo ampliado a estimar es:

$$
\begin{aligned}
\text { GINI }_{t}= & \beta_{0}+\beta_{1} L N\left(I P C F D_{i t}\right)+\beta_{2} L N\left(I P C F D_{i t}\right)^{2}+\beta_{3} P A_{i t} \\
& +\beta_{4} P M_{i t}+\beta_{5} P C O N S T_{i t}+\beta_{6} P C R H_{i t}+\beta_{7} P S E R V_{i t} \\
& +\beta_{8} L N\left(I N V_{i t}\right)+\beta_{9} C A_{i t}+\beta_{10} A E B_{i t}+\beta_{11} A E S_{i t} \\
& +\beta_{12} P C E S_{i t}+\beta_{13} P U_{i t}+\beta_{14} E P_{i t}+\beta_{15} P C S_{i t} \\
& +\beta_{16} T O_{i t}+\beta_{17} T D_{i t}+\mu_{i t}
\end{aligned}
$$

\section{Crecimiento EConómico e indicadores socioeconómicos de Colombia}

Uno de los aspectos que se destaca en este documento es la heterogeneidad en los niveles de vida y en el desarrollo económico de los departamentos y regiones en Colombia, para introducir el estudio de esas diferencias en esta sección se realizará un análisis descriptivo de la tendencia del crecimiento económico por departamentos, y se presenta una caracterización socioeconómica, a partir de la revisión de indicadores laborales, educativos y de desigualdad.

\section{Crecimiento económico por departamentos}

El crecimiento económico en Colombia durante el periodo 2002-2016 ha mostrado tasas positivas, sin embargo, la situación en cada departamento ha reflejado heterogeneidades en sus niveles de crecimiento, debido a que algunos departamentos presentaron tasas negativas en contraste al nacional, este es el caso de La Guajira 
$(-16,17 \%)$ en 2002, Caquetá (-4,35\%) en 2004, Huila en 2005 (-5,34\%), Córdoba en 2008 (-4,15\%), Caldas en 2009 (-4,3\%) (Figura 1). No obstante, cabe resaltar que desde el año 2002 la economía colombiana inició un periodo de recomposición macroeconómica posterior a la crisis de fin de siglo, lo que trajo como consecuencia mejoras en la capacidad productiva e incrementos en la inversión privada, alcanzando un tope de crecimiento de $6,7 \%$ en 2007.

Como se observa en la Figura 1 en el periodo 2007-2010 el crecimiento económico registró una reducción pasando de 6,7\% en el 2007 a 3,8\% en el 2010, explicado entre otras razones por la crisis económica internacional y factores como la caída del dólar, la disminución en el precio del petróleo y la baja productividad de los distintos sectores económicos (Casas, 2017; García, 2015; González, Galeano y Trejos, 2015). No obstante, en algunos departamentos del país hubo un buen desempeño económico con tasas de crecimiento entre 5,8\% y 17,6\% (Boyacá, Chocó y Meta).

A partir del 2011, la economía colombiana enfrentó una coyuntura económica derivada de la caída del precio de los commodities que afectó las reservas internacionales, la deuda externa y el crecimiento económico del país (Casas, 2017; García, 2015). Además, otros departamentos como Antioquia, Cundinamarca, Tolima y la ciudad de Bogotá, D.C han tenido una tasa de crecimiento similar a la del país; sin embargo, cabe resaltar que la dinámica del crecimiento económico del total nacional no se ve reflejada en la situación departamental.
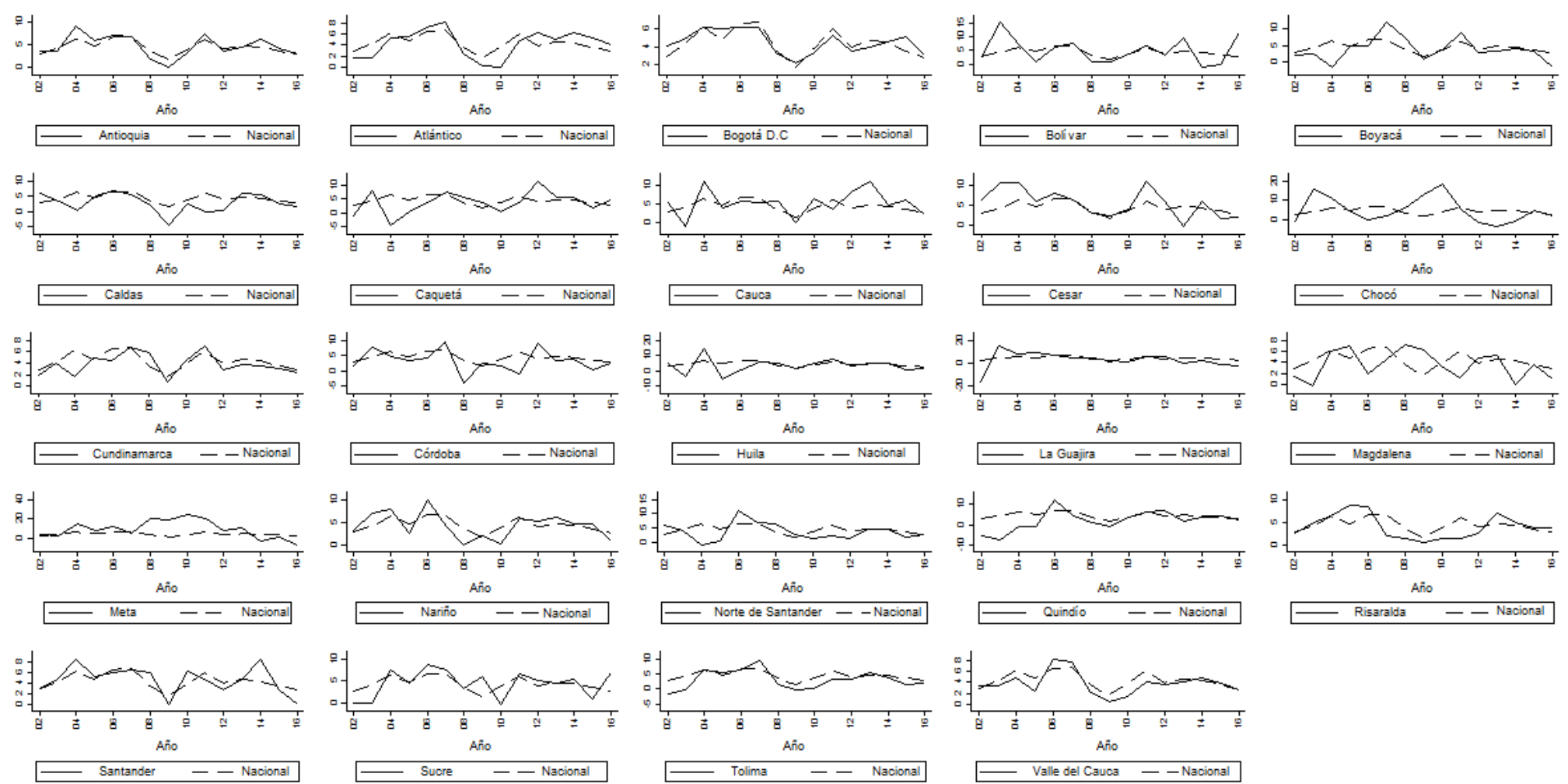

Figura 1. Tasa de crecimiento a nivel departamental y nacional 2002-2016.

Nota: El total nacional se elaboró a partir de la sumatoria del subtotal valor agregado de los 23 departamentos y la ciudad de Bogotá D.C.

Fuente: Elaboración propia con base en cuentas nacionales (DANE, 2017b). 


\section{Indicadores socioeconómicos ${ }^{13}$}

\section{- Indicadores laborales}

Durante el periodo 2002-2016 la Tasa Global de Participación (TGP) en Colombia creció en 4,0\%, explicado por un incremento en la Población Económicamente Activa (PEA), el cual pasó de 18 millones de personas en 2002 a 24 millones en 2016 (incremento de 33\% aproximadamente); mientras que la Población en Edad de Trabajar (PET) aumento en menor proporción que la PEA en un 25,1\%, lo que indica una transición de la población económicamente inactiva a la PEA sea como ocupado o en busca de algún tipo de trabajo.

TGP (EJE IZQ)

PEA (EJE DER)
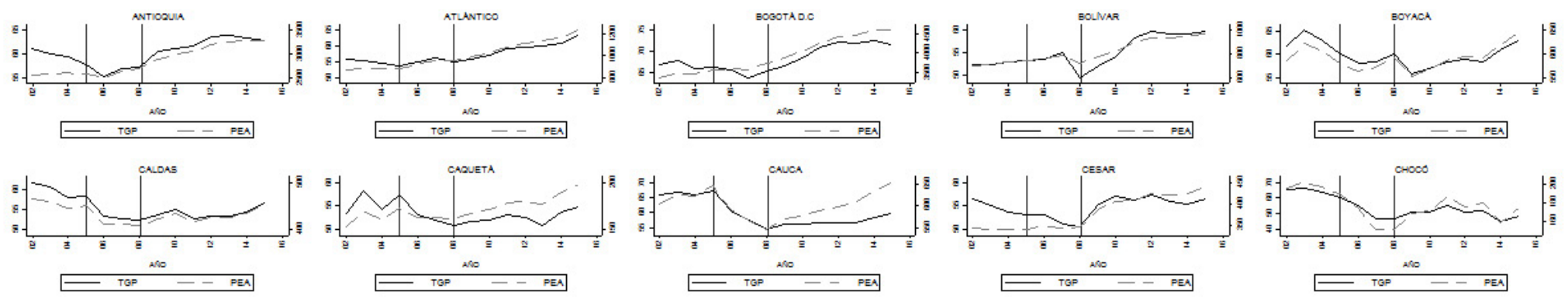

${ }_{\text {TGP }}^{N O S}-{ }_{P E A}$
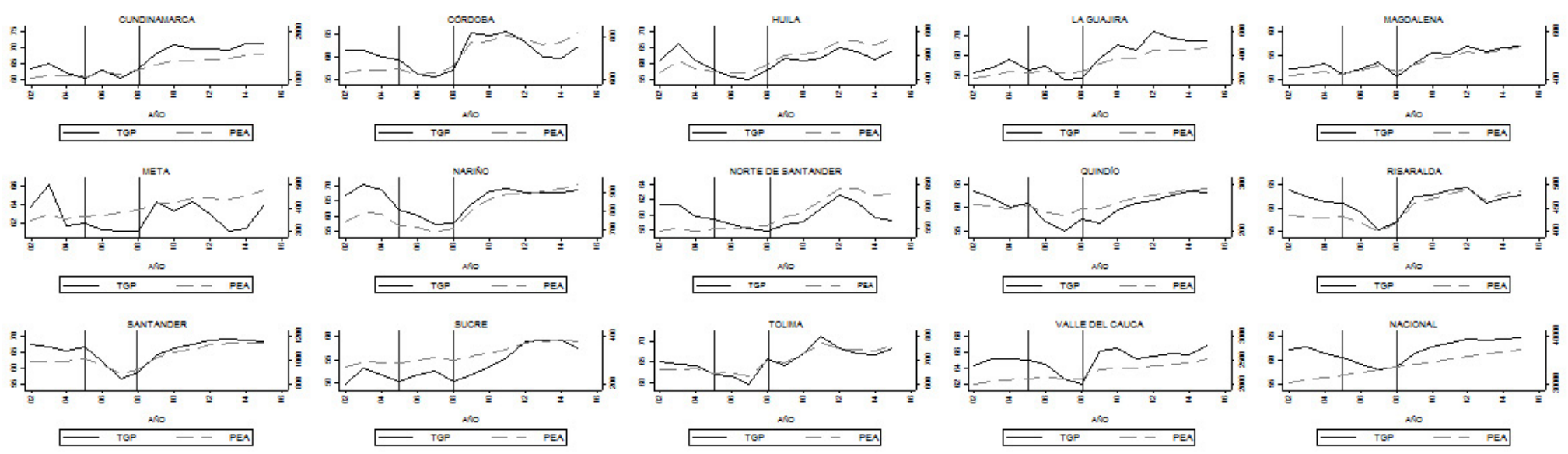

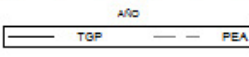

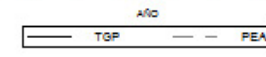

—TGP

Figura 2. Tasa global de participación y población económicamente activa a nivel departamental y nacional 2002-2016.

Nota 1: La TGP y PEA en el periodo 2006-2007 presentan problemas en los datos, debido al cambio de metodología que pasó de la ECH a la GEIH.

Nota 2: Datos de la PEA expresados en miles de personas.

Fuente: Elaboración propia con base en mercado laboral (DANE, 2017a).

\footnotetext{
${ }^{13}$ En esta sección se realizará el análisis para el periodo 2002-2016. Sin embargo, por restricciones de espacio solamente se presentan indicadores laborales para el último año.
} 
Los departamentos que han presentado una tendencia similar en la TGP y la PEA fueron Antioquia, Boyacá, Nariño, Tolima y Santander. Por otro lado, los departamentos como Caldas, Cauca, Chocó y Norte de Santander obtuvieron una reducción en la TGP de (-9,8\%), (-8,60\%), (-22,25\%) y (-3,07\%) respectivamente (Figura 2), lo anterior evidencia las heterogeneidades en los cambios del mercado laboral entre departamentos.

Además, los departamentos con mayor participación en la PET en el 2016 fueron Bogotá, D.C (81,9\%), Caldas (81,7\%), Risaralda (81,8\%) y Valle del Cauca (81,8\%); mientras que Caquetá $(75,5 \%)$, Chocó $(72,2 \%)$, La Guajira $(72,4 \%)$ y Magdalena $(75,2 \%)$ tuvieron las cifras más bajas en este indicador (Figura 3). Esto explica las diferencias en la estructura demográfica, puesto que en el Chocó y La Guajira se observa una mayor tasa de dependencia debido a que la tercera parte de su población son niños.

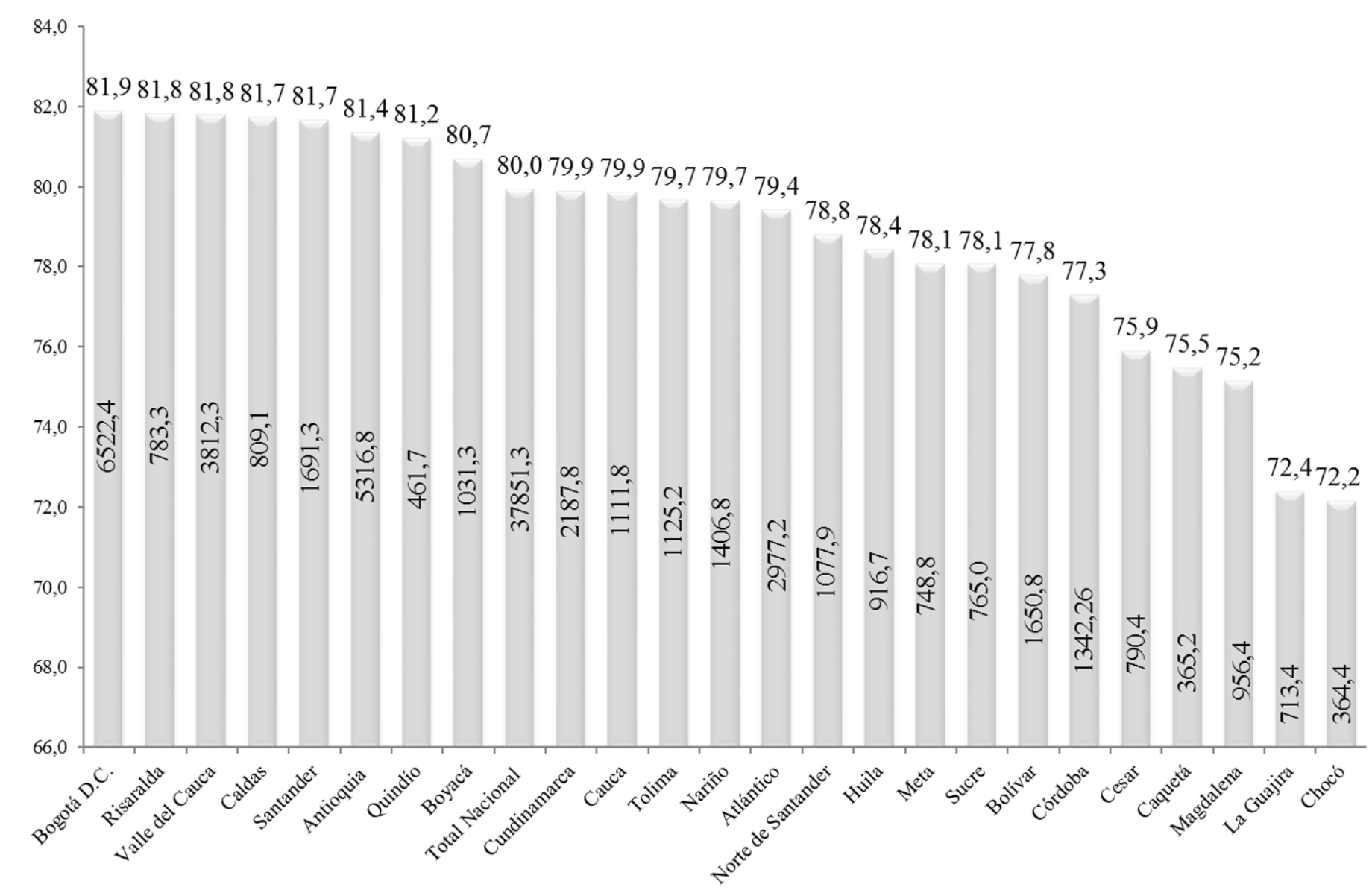

Figura 3. Porcentaje de la Población en Edad de Trabajar (PET) a nivel departamental 2016.

$$
\begin{aligned}
& \text { Nota 1: Los datos que se encuentran en el interior de las barras hacen } \\
& \text { referencia al número de personas, expresado en miles. }
\end{aligned}
$$

Nota 2: La población que contempla la edad de trabajar es: mayores de 12 años en áreas urbanas y 10 años en áreas rurales.

Fuente: Elaboración propia con base en mercado laboral (DANE, 2017a).

En Colombia la tasa de desempleo se redujo notablemente entre 2002 y 2016 pasando de $15,5 \%$ a $9,2 \%$. No obstante, hay considerables heterogeneidades en este indica- 
dor por departamento, para el caso de Quindío y Norte de Santander se reflejó una TD, en promedio, del 17,0\% y 13,2\% respectivamente; mientras que Bolívar, Boyacá y Caquetá fueron de las más bajas (Figura 4). Además, una parte de la reducción del desempleo se debe a la absorción de trabajadores en el sector informal, ocasionado por el incremento de trabajos domésticos y cuenta propia.

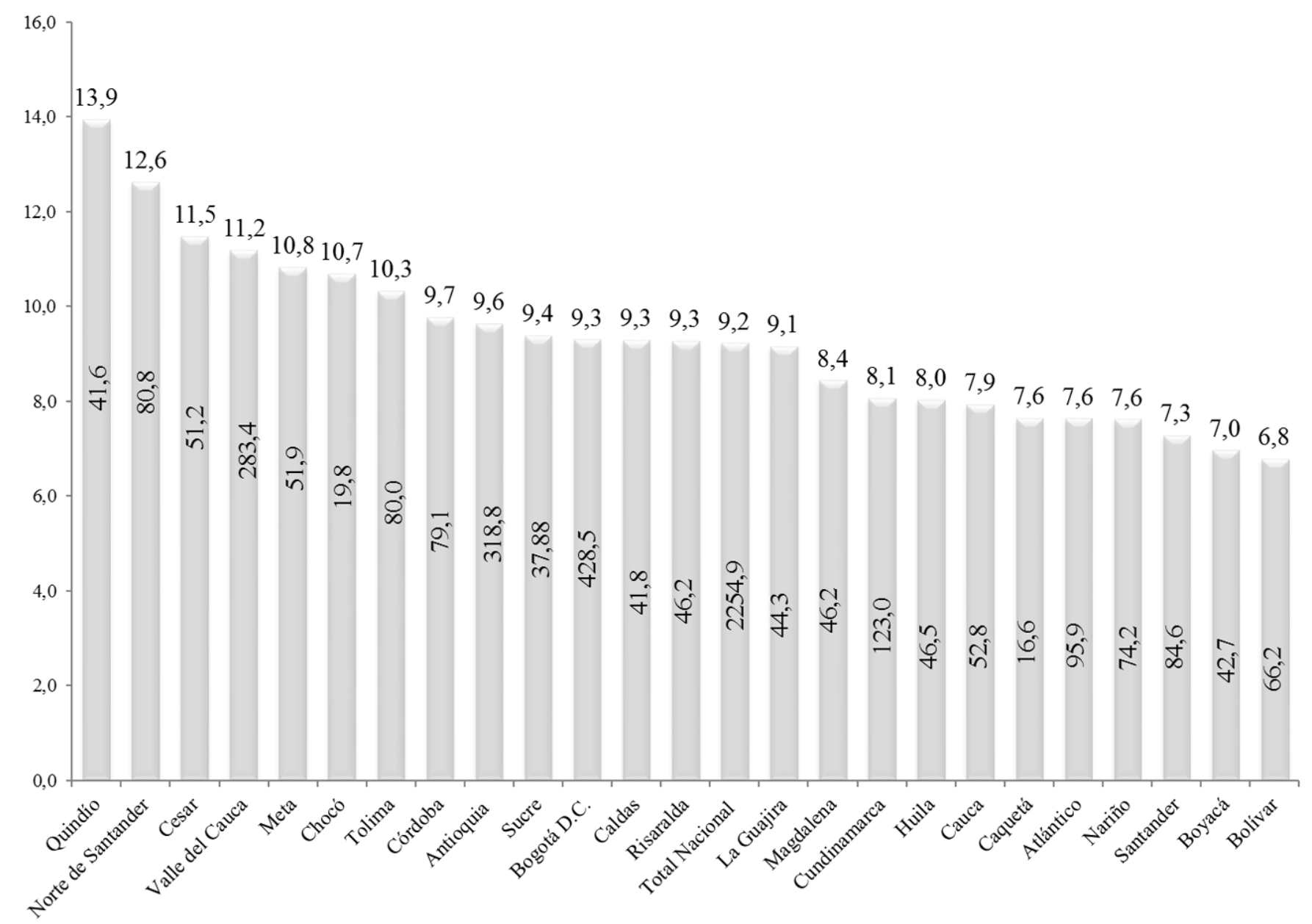

Figura 4. Tasa de desempleo a nivel departamental 2016.

Nota: Los datos que se encuentran en el interior de las barras hacen referencia al número de personas, expresado en miles.

Fuente: Elaboración propia con base en mercado laboral (DANE, 2017a).

Por último, es importante resaltar que en el período 2002-2016 en la mayoría de los departamentos se reflejó el denominado "bono demográfico" (Figura 2), entendido como la mayor proporción de personas en edad de trabajar, lo que trae consigo una reducción en la tasa de dependencia, es decir, un aumento en los trabajadores por hogar contribuyendo a mejorar los indicadores laborales y socioeconómicos de un país.

\section{- Niveles educativos}

Una de las dimensiones esenciales en el estudio del crecimiento y desarrollo económico de un país es la formación educativa. Durante el periodo 2008-2016

${ }^{14}$ No se consideraron los años entre 2002 y 2005, por la falta de información en la ECH y su comparabilidad con la GEIH. 
en Colombia se ha reflejado un avance moderado en algunos indicadores que evidencian mejoras en el sistema educativo: en primer lugar, la asistencia a centros de educación básica ha tenido un aumento de 3,34\% y el de educación superior ha disminuido 4,6\%; posteriormente, los años promedio de escolaridad incrementaron de $7,54 \%$ en 2008 a $8,35 \%$ en 2016; y finalmente, los niveles de analfabetismo se han reducido en $1,91 \mathrm{pp}$.

A partir de los resultados obtenidos a nivel departamental, la asistencia a educación básica presentó incrementos en todos los departamentos a diferencia de la asistencia a educación superior que ha disminuido de manera significativa (en términos porcentuales). Los departamentos con más años promedio de escolaridad fueron Antioquia $(8,5)$, Atlántico $(9,1)$, Valle del Cauca $(8,5)$ y la ciudad de Bogotá D.C $(10,3)$ para el 2016 (Figura 5 y Anexo 1). Esto se debe a que las personas tienen mayores oportunidades para acceder a la educación sea básica o superior.

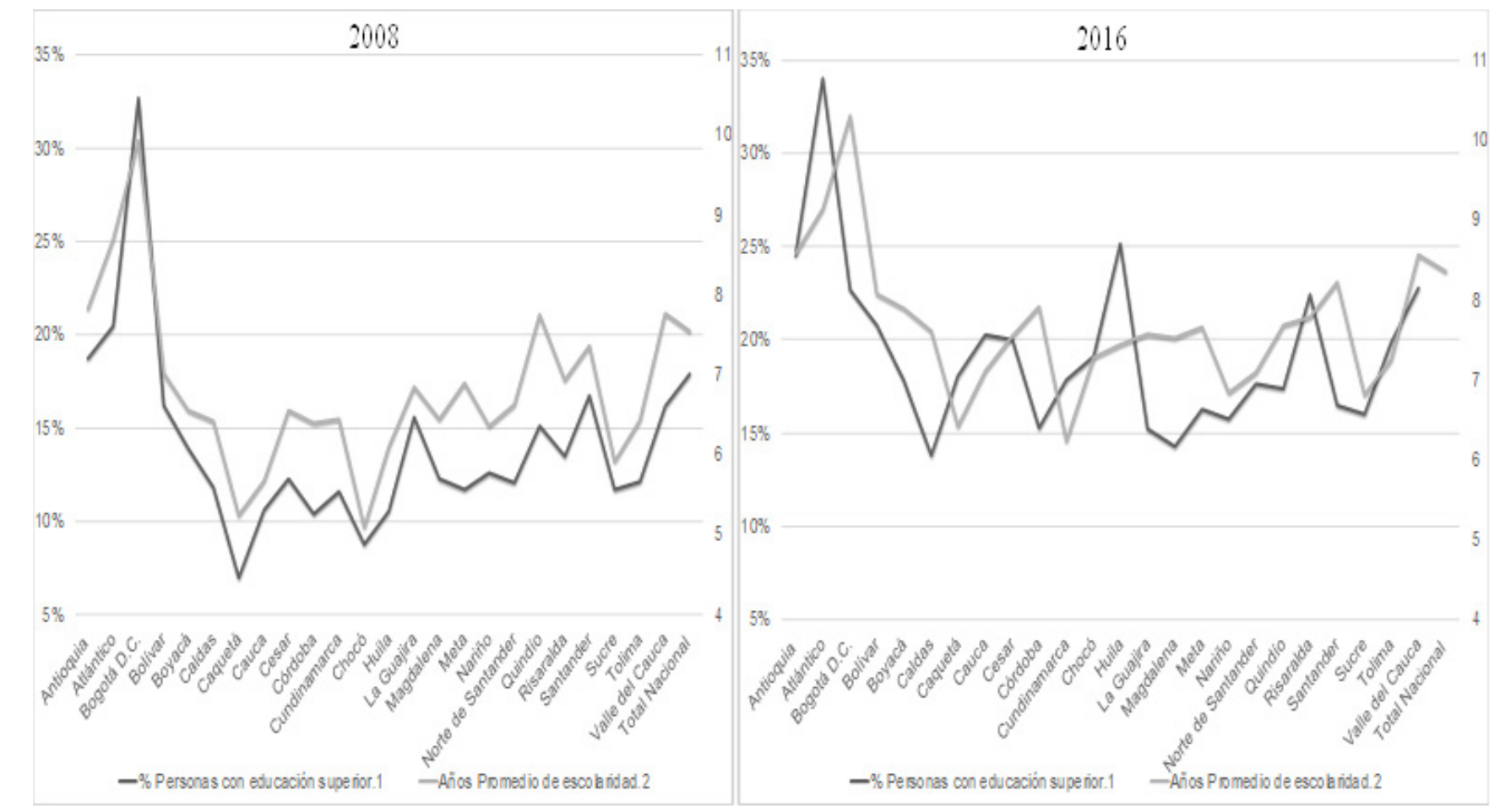

Figura 5. Indicadores educativos por departamento 2008 - 2016

Nota 1: Las personas con educación superior contempla la población mayor a 26 años de edad.

Nota 2: La edad promedio contempla la población mayor a 26 años de edad.

Fuente: Elaboración propia a partir de DANE (2017a).

De igual forma, para el año 2016 los departamentos de Cesar, Chocó y La Guajira obtuvieron elevadas tasas de analfabetismo de 17,1\%, 23,9\% y 19,5\%, y los años de escolaridad, en promedio, fueron de $(7,5),(6,2)$ y $(7,5)$ respectivamente; una de las razones que explica este problema es que los jóvenes desisten de la formación educativa por motivos, tales como: la necesidad de trabajar para ayudar a la familia en el sustento diario o no tienen los recursos suficientes para sostener lo que requiere la vida estudiantil. 


\section{- Niveles de ingreso y desigualdad}

Otro factor determinante para medir el bienestar de la población de un país es la desigualdad en la distribución de la riqueza y el ingreso. Colombia durante el periodo 2002-2016 ha mostrado una mejora leve en términos de desigualdad, lo que se observa a partir de la reducción del coeficiente de Gini que pasó de 0,57 en 2002 a 0,52 en 2016; sin embargo, en el año 2012 el Banco Mundial ubicó a Colombia como el tercer país con mayor inequidad de los países de referencia (The World Bank, 2017).

TABLA 2.

Índice de los ingresos per cápita familiar, coeficiente de Gini e indice de Theil por departamento 2002, 2005, 2008 y 2016

\begin{tabular}{|c|c|c|c|c|c|c|c|c|c|c|c|c|}
\hline \multirow{2}{*}{$\begin{array}{c}\text { AÑO } \\
\text { DEPARTAMENTO }\end{array}$} & \multicolumn{3}{|c|}{2002} & \multicolumn{3}{|c|}{2005} & \multicolumn{3}{|c|}{2008} & \multicolumn{3}{|c|}{2016} \\
\hline & IPCF & GINI & THEIL & IPCF & GINI & THEIL & IPCF & GINI & THEIL & IPCF & GINI & THEIL \\
\hline Antioquia & 110,20 & 0,569 & 0,727 & 110,35 & 0,551 & 0,624 & 116,02 & 0,578 & 0,674 & 116,85 & 0,505 & 0,500 \\
\hline Atlántico & 102,36 & 0,534 & 0,572 & 89,54 & 0,512 & 0,550 & 83,25 & 0,502 & 0,514 & 90,62 & 0,437 & 0,374 \\
\hline Bogotá & 176,68 & 0,544 & 0,569 & 179,54 & 0,556 & 0,615 & 180,85 & 0,529 & 0,555 & 168,75 & 0,497 & 0,496 \\
\hline Bolivar & 64,15 & 0,529 & 0,551 & 71,47 & 0,482 & 0,447 & 65,08 & 0,550 & 0,606 & 70,49 & 0,480 & 0,445 \\
\hline Boyacá & - & - & - & - & - & - & 67,47 & 0,556 & 0,578 & 84,00 & 0,530 & 0,560 \\
\hline Caldas & 87,30 & 0,504 & 0,500 & 83,99 & 0,502 & 0,498 & 86,72 & 0,544 & 0,602 & 89,18 & 0,507 & 0,523 \\
\hline Caquetá & - & - & - & - & - & - & 64,48 & 0,476 & 0,443 & 62,25 & 0,460 & 0,432 \\
\hline Cauca & - & - & - & - & - & - & 53,08 & 0,575 & 0,640 & 56,21 & 0,499 & 0,478 \\
\hline Cesar & - & - & - & - & - & - & 52,82 & 0,541 & 0,583 & 63,00 & 0,471 & 0,422 \\
\hline Chocó & - & - & - & - & - & - & 46,76 & 0,597 & 0,744 & 43,15 & 0,569 & 0,644 \\
\hline Córdoba & 58,60 & 0,545 & 0,592 & 64,21 & 0,534 & 0,568 & 58,85 & 0,523 & 0,554 & 60,91 & 0,468 & 0,443 \\
\hline Cundinamarca & - & - & - & - & - & - & 83,89 & 0,457 & 0,393 & 97,80 & 0,431 & 0,352 \\
\hline Huila & - & - & - & - & - & - & 64,13 & 0,573 & 0,671 & 67,73 & 0,520 & 0,502 \\
\hline La Guajira & - & - & - & - & - & - & 48,94 & 0,558 & 0,611 & 61,00 & 0,532 & 0,536 \\
\hline Magdalena & - & - & - & - & - & - & 55,02 & 0,559 & 0,645 & 56,66 & 0,486 & 0,446 \\
\hline Meta & 85,10 & 0,476 & 0,445 & 91,76 & 0,491 & 0,484 & 98,13 & 0,496 & 0,483 & 89,86 & 0,458 & 0,415 \\
\hline Nariño & 59,23 & 0,518 & 0,539 & 61,24 & 0,506 & 0,493 & 61,90 & 0,532 & 0,582 & 63,81 & 0,522 & 0,536 \\
\hline Norte de Santander & 71,01 & 0,483 & 0,470 & 62,96 & 0,487 & 0,472 & 73,13 & 0,498 & 0,484 & 65,99 & 0,474 & 0,424 \\
\hline Quindío & - & - & - & - & - & - & 95,45 & 0,560 & 0,670 & 83,50 & 0,464 & 0,436 \\
\hline Risaralda & 104,91 & 0,495 & 0,496 & 97,86 & 0,505 & 0,508 & 94,91 & 0,510 & 0,512 & 91,22 & 0,437 & 0,367 \\
\hline Santander & 100,99 & 0,531 & 0,539 & 100,52 & 0,520 & 0,523 & 108,73 & 0,476 & 0,417 & 104,79 & 0,445 & 0,374 \\
\hline Sucre & - & - & - & - & - & - & 50,76 & 0,527 & 0,563 & 56,68 & 0,466 & 0,430 \\
\hline Tolima & 75,40 & 0,517 & 0,513 & 71,06 & 0,493 & 0,481 & 75,27 & 0,509 & 0,497 & 80,68 & 0,482 & 0,457 \\
\hline Valle del Cauca & 119,39 & 0,528 & 0,572 & 120,67 & 0,538 & 0,599 & 109,26 & 0,517 & 0,543 & 108,59 & 0,485 & 0,484 \\
\hline
\end{tabular}

Nota: El computo del IPCF para esta tabla y el resto del documento está a precios constantes con año base 2016. Los precios se deflactaron con el IPC del DANE. El dato del IPCF es la relación porcentual entre el promedio del departamento y el promedio del total nacional.

Fuente: Elaboración propia con base en la ECH y GEIH (DANE, 2017a).

Colombia presenta amplias heterogeneidades en los niveles de desigualdad e ingreso entre departamentos. No obstante, departamentos con elevados niveles de ingreso no son los mismos que presentan un patrón claro de elevada o baja desigualdad en el ingreso. Los tres principales departamentos del país (Antioquia, Santander y Valle del Cauca) y la ciudad de Bogotá, tienen niveles de ingreso muy por encima del promedio nacional, a pesar de esto, Antioquia es uno de los departamentos con mayor nivel de desigualdad, en contraste con Santander que presenta índices bajos. La reducción de la desigualdad en el periodo 2002-2016 presentada en el agregado nacional, se reflejó en un descenso en los niveles de desigualdad en la mayoría de departamentos del país. 


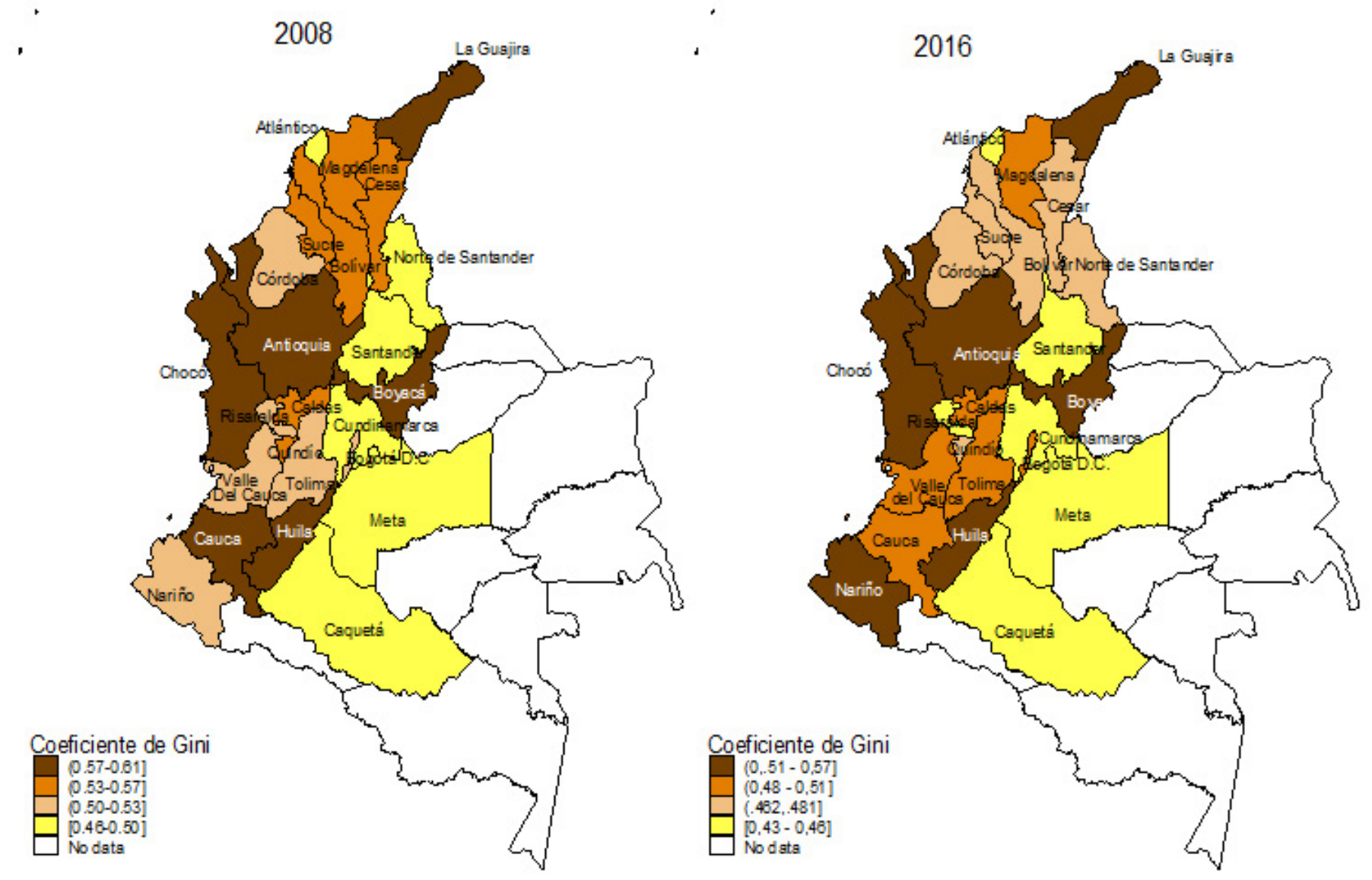

Figura 6. Niveles de desigualdad en Colombia por departamentos 2008 y 2016 Fuente: Elaboración propia con base en la GEIH (DANE, 2017a).

Una heterogeneidad percibida en este trabajo en términos de inequidad es que la desigualdad no está geográficamente concentrada, sino que está espacialmente distribuida; como se pueden contemplar en la Figura 6 y la Tabla 2, departamentos de la región Caribe como Atlántico y Sucre presentan bajos niveles de desigualdad a diferencia de Bolívar y La Guajira que son muy desiguales; mientras que en la región Andina Oriental como el caso de Cundinamarca es el más equitativo en el IPCF en comparación con Boyacá que está en el top del ranking de los más inequitativos del país.

A partir de lo anterior, Colombia a nivel departamental ha mostrado mejoras en los indicadores socioeconómicos y laborales para el periodo analizado, pero aún se perciben dificultades en aspectos como: la baja cobertura en educación superior o profesional, altos niveles de analfabetismo, aumento en el empleo informal e inequidad entre grupos sociales. Estos problemas son ocasionados por factores como la concentración de la riqueza, la poca inversión en infraestructura y las falencias que hay en la planificación e implementación de las políticas públicas que no se ajustan a las necesidades de la población colombiana. Finalmente, en la siguiente sección se analizará la relación entre los niveles de ingreso y su desigualdad de manera sistemática y robusta por medio de estimaciones econométricas preliminares y la aplicación de la metodología de datos panel para los periodos 2002-2005 y $2008-2016$. 


\section{Resultados Econométricos ${ }^{15}$}

En este estudio se estima la relación entre los niveles de ingreso y la desigualdad con diferentes metodologías y especificaciones econométricas con el objetivo de encontrar o descartar robustez en los resultados. Se estima a partir de Mínimos Cuadrados Ordinarios para datos de corte transversal, primera diferencia y datos panel por efectos fijos, y Mínimos Cuadrados Generalizados para la técnica de efectos aleatorios con regresiones lineales simples y múltiples. Las especificaciones y las variables utilizadas en la estimación se presentaron en la sección 2.

A partir de los resultados obtenidos de las estimaciones econométricas de las especificaciones (3) a (8) para el periodo 2002-2005, se obtuvo que en la regresión lineal simple (RLS) el $L N(I P C F D)$ y el coeficiente de Gini y el índice de Theil tienen una relación positiva. Luego, al incluir la forma cuadrática del $L N(I P C F D)$ se observó que es estadísticamente significativa y se presenta una relación en forma de "U" entre los niveles de desigualdad y el nivel de ingreso (Anexo 2).

TABLA 3.

Estimaciones MCO sobre el coeficiente de Gini por departamento 2008-2016

\begin{tabular}{|c|c|c|c|c|c|c|c|c|c|c|c|c|}
\hline \multirow[b]{2}{*}{ Variables independientes } & \multicolumn{4}{|c|}{$1^{\text {a }}$ especificación } & \multicolumn{4}{|c|}{ 2a especificación } & \multicolumn{4}{|c|}{ 3a especificación } \\
\hline & RLS & RLS2 & $\begin{array}{c}\text { RLS } \\
\text { dummy año }\end{array}$ & $\begin{array}{c}\text { RLS 2 } \\
\text { dummy año }\end{array}$ & RLM $X^{\prime}$ & RLM X' 2 & $\begin{array}{c}\text { RLM X' } \\
\text { dummy } \\
\text { años }\end{array}$ & $\begin{array}{c}\text { RLMX' } 2 \\
\text { dummy } \\
\text { años }\end{array}$ & RLM $X^{\prime}$ & RLM X' 2 & $\begin{array}{c}\text { RLM X' } \\
\text { dummy } \\
\text { años }\end{array}$ & $\begin{array}{c}\text { RLM X' } 2 \\
\text { dummy } \\
\text { años }\end{array}$ \\
\hline Regresiones & (1) & (2) & (3) & (4) & (5) & (6) & (7) & (8) & (9) & (10) & (11) & (12) \\
\hline $\mathrm{LN}(\mathrm{IPCFD})$ & $-0,0432 * * *$ & $-2,3550 * * *$ & $-0,0339 * * *$ & $-2.1229^{* * * *}$ & $-0,0587^{* * * * *}$ & $-1,8361^{* * *}$ & $-0,0379 * * *$ & $-0,3715$ & $-0,0317$ & $-1,5377^{* * * *}$ & $-0,0447 * *$ & $-0,0562$ \\
\hline LN(IPCFD) CUADRADO & - & $0,0884 * * *$ & - & $0,0798^{* * * *}$ & - & $0,0685^{* * *}$ & - & 0,0128 & - & $0,0570 * * *$ & - & 0,0004 \\
\hline D09 & - & - & $-0,0024$ & 0,0008 & - & - & $-0,0032$ & $-0,0028$ & - & - & $-0,0065$ & $-0,006$ \\
\hline D10 & - & - & $-0,0056$ & $-0,0020$ & - & - & $-0,0103$ & $-0,0095$ & - & - & $-0,0128$ & $-0,0128$ \\
\hline D11 & - & - & $-0,0125$ & $-0,0069$ & - & - & $-0,01873^{* *}$ & $-0,0176^{* *}$ & - & - & $-0,0242^{* * *}$ & $-0,0241^{* * *}$ \\
\hline D12 & - & - & $-0,0123$ & $-0,0063$ & - & - & $-0,0234 * *$ & $-0,0218 * *$ & - & - & $-0,0348^{* * * *}$ & $-0,0347 * * *$ \\
\hline D13 & - & - & $-0,0177 *$ & $-0,0113$ & - & - & $-0,0345 * * *$ & $-0,0325 * * *$ & - & - & $-0,0581$ **** & $-0,0580^{* * * *}$ \\
\hline D14 & - & - & $-0,0182 *$ & $-0,0122$ & - & - & $-0,0412 * * *$ & $-0,0388 * * *$ & - & - & $-0,0671 * * *$ & $-0,0670 * * *$ \\
\hline D15 & - & - & $-0,0299 * * * *$ & $-0,0231^{* * *}$ & - & - & $-0,0539 * * *$ & $-0,0513 * * *$ & - & - & $-0,0795$ & $-0,0795 * * *$ \\
\hline D16 & - & - & $-0,0372 * * *$ & $-0,0300^{* * * *}$ & - & - & $-0,0659 * * *$ & $-0,0629 * * *$ & - & - & $-0,0895 * * *$ & $-0,0895 * * *$ \\
\hline PIM & - & - & - & - & $-0,0003$ & $-0,0000$ & $-0,0010^{* * * *}$ & $-0,0009 * * *$ & - & - & - & - \\
\hline PA & - & - & - & - & - & - & - & - & 0,0007 & 0,0008 & $0,0030^{* * *}$ & $0,0030^{* * * *}$ \\
\hline PM & - & - & - & - & - & - & - & - & $0,0007 *$ & 0,0005 & $0,0026 * * *$ & $0,0026^{* * *}$ \\
\hline PCONST & - & - & - & - & - & - & - & - & 0,0012 & 0,0013 & $0,0049^{\text {*** }}$ & $0,0049 * * *$ \\
\hline PCRH & - & - & - & - & - & - & - & - & $-0,0009$ & $-0,0012$ & $-0,0020^{* *}$ & $-0,0020^{* *}$ \\
\hline PSERV & - & - & - & - & - & - & - & - & 0,0008 & 0,0004 & $0,0030 * * *$ & $0,0030 * * *$ \\
\hline LN(INV) & - & - & - & - & - & - & - & - & 0,0087 & 0,0069 & $0,0265^{* * *}$ & $0,0265^{* * *}$ \\
\hline $\mathrm{CA}$ & - & - & - & - & 0,00005 & 0,00009 & $-0,00004$ & $-0,00003$ & 0,00004 & 0,00008 & 0,0001 & 0,0001 \\
\hline AEB & - & - & - & - & - & - & - & - & $-0,0009$ & $-0,0013$ & 0,0009 & 0,0009 \\
\hline AES & - & - & - & - & - & - & - & - & $0,0021 * * *$ & $0,0016 * *$ & 0,0002 & 0,0002 \\
\hline PCES & - & - & - & - & $0,0035 * * *$ & $0,0019 * *$ & $0,0057 * * *$ & $0,0053 * * *$ & $0,0030^{* *}$ & $0,0023^{*}$ & $0,0056 * * *$ & $0,0056 * * *$ \\
\hline PU & - & - & - & - & $-0,0007^{* * *}$ & $-0,0006^{* *}$ & $-0,0015^{* * * *}$ & $-0,0015^{* * * *}$ & $-0,0010$ & $-0,0006$ & $-0,0018^{* * * *}$ & $-0,0018^{* * * *}$ \\
\hline EP & - & - & - & - & - & - & - & - & 0,0006 & 0,0030 & 0,0075 **** & $0,0075^{* * * * *}$ \\
\hline PCS & - & - & - & - & - & - & - & - & $-0,0017$ & $-0,0011^{*}$ & $-0,0006$ & $-0,0006$ \\
\hline TO & - & - & - & - & - & - & - & - & $-0,0010$ & $-0,0009$ & $-0,0018^{* * * *}$ & $-0,0018^{* * * *}$ \\
\hline id & - & - & - & - & $0,0034 * * *$ & $0,0028 * * *$ & 0,0010 & 0,0010 & $0,0028 * *$ & $0,0024 * *$ & 0,0005 & 0,0005 \\
\hline$\beta \quad$ (Intercepto) & $1,0716 * * *$ & $16.1686 * * *$ & $0,9657 * * *$ & $14,6150^{* * *}$ & $1,2306 * * *$ & $12,7668 * * *$ & $1,0465 * * *$ & 3,2149 & $1,0045 * * *$ & $10,8855 *$ & $0,6021 * *$ & 0,6790 \\
\hline $\mathrm{N}^{\circ}$ observaciones & 216 & 216 & 216 & 216 & 216 & 216 & 216 & 216 & 216 & 216 & 216 & 216 \\
\hline R Cuadrado & 0,1414 & 0,2631 & 0,2321 & 0,3282 & 0,2616 & 0,3155 & 0,4571 & 0,4586 & 0,3976 & 0,4196 & 0,6030 & 0,6030 \\
\hline Signific ancia global - p-valor & 0,0000 & 0,0000 & 0,0000 & 0,0000 & 0,0000 & 0,0000 & 0,0000 & 0,0000 & 0,0000 & 0,0000 & 0,0000 & 0,0000 \\
\hline
\end{tabular}

Nota 1: Las estimaciones presentan significancia de: $1 \%\left(^{* * *}\right), 5 \%\left(^{(*)}\right)$ y $10 \%\left({ }^{*}\right)$.

Nota 2: Los resultados de las estimaciones son robustos para evitar problemas de heterocedasticidad.

Fuente: Elaboración propia.

En la primera especificación con la forma lineal y cuadrática (3) y (4), al incluir las variables dummy de años, se observa que no hay cambios significativos en los

${ }_{15}$ En esta sección se incluyen las tablas de los resultados de las estimaciones para el coeficiente de Gini, y en el anexo se incluyen los resultados de las estimaciones para datos panel del índice de Theil. 
niveles de desigualdad respecto al año 2002, dado que los parámetros no son significativos en las estimaciones ilustradas en el Anexo 2. En la segunda especificación con la forma lineal del logaritmo (5) y (7) la relación no es significativa, mientras que en la forma cuadrática (6) y (8) la relación es negativa, ya que para ningún dato de la muestra la primera derivada es positiva, indicando que los departamentos con menor ingreso tendrían mayores niveles de desigualdad. Finalmente, en la tercera especificación cuando se controla con todas las variables planteadas en la ecuación (8) se pierde la significatividad del IPCFD, indicando que la posible importancia de esta variable sobre la desigualdad podría ser resultado de las variables omitidas y el consecuente problema de endogeneidad.

En las estimaciones del periodo 2008-2016 se tienen resultados diferentes, respecto a las del periodo 2002-2005, en las especificaciones con $L N(I P C F D)$ lineal, en la importancia de los años en los cambios de la desigualdad y en la significatividad estadística de las variables de control incluidas en las especificaciones 2 y 3 . En todas las especificaciones lineales se tiene un coeficiente estimado negativo y estadísticamente significativo (excepto en la 9), indicando una relación inversa entre los niveles de ingreso y de desigualdad. En las estimaciones con $L N(I P C F D)$ lineal y cuadrático se observa que la relación tiene forma de "U", decreciente para ciertos valores y creciente a partir de un valor crítico, sin embargo, en todas las estimaciones la mayoría de observaciones se encuentran en la parte decreciente de la relación [96\% en (2) y (4), 87\% en (6), y 91\% en (10)], indicando que la relación en la mayoría de los casos predichos y para el promedio, es inversa (Tabla 3). De este modo, Colombia a nivel departamental no se cumple la curva de Kuznets para modelos de regresión lineal estimados por MCO considerando las distintas especificaciones planteadas en este trabajo.

$\mathrm{Al}$ observar el resto de variables incluidas en las especificaciones 2 y 3 , se observan cuatro resultados que se confirman en las distintas especificaciones: el efecto del mayor capital humano (PCES), el rol de la industria manufacturera, la importancia de la concentración poblacional por área geográfica, y los cambios en los niveles de desigualdad en el tiempo.

En las estimaciones de primera diferencia para el 2002-2005 se evidenció que el $L N(I P C F D)$ y su correspondiente relación cuadrática no tienen vínculo con los indicadores de desigualdad (Anexo 3). Además, se observó que en todas las variables de control no presentaron significancia estadística, esto se explica en parte, porque el periodo es muy limitado y el tamaño muestral reducido.

Para el periodo 2008-2016 al realizar las respectivas regresiones sobre el coeficiente de Gini y el índice de Theil se puede contemplar que los parámetros estimados para el $L N(I P C F D)$ son positivos y significativos para las especificaciones lineales. Sin embargo, al incorporar la relación cuadrática se pierde la significancia de la variable lineal, pero se mantienen la de la variable al cuadrado, indicando problemas de especificación, y se confirmaría la relación positiva entre los niveles de ingreso y su desigualdad (Tabla 4). 
TABLA 4.

Estimaciones de primera diferencia sobre el coeficiente de Gini 2008-2016

\begin{tabular}{|c|c|c|c|c|c|c|c|c|c|c|c|c|}
\hline \multirow[b]{2}{*}{$\begin{array}{c}\text { Variables independientes } \\
\text { Regresiones }\end{array}$} & \multicolumn{4}{|c|}{ 1" especificación } & \multicolumn{4}{|c|}{ 2" especificación } & \multicolumn{4}{|c|}{ 3a especificación } \\
\hline & $\begin{array}{l}\text { RLS } \\
(1)\end{array}$ & $\begin{array}{c}\text { RLS2 } \\
\text { (2) }\end{array}$ & $\begin{array}{c}\text { RLS } \\
\text { dummy año } \\
(3) \\
\end{array}$ & $\begin{array}{c}\text { RLS } 2 \\
\text { dummy año } \\
(4)\end{array}$ & $\begin{array}{c}\text { RLM X' } \\
\text { (5) } \\
\end{array}$ & $\begin{array}{c}\text { RLM X' } 2 \\
\text { (6) }\end{array}$ & $\begin{array}{c}\text { RLM X' } \\
\text { dummy } \\
\text { años } \\
(7) \\
\end{array}$ & $\begin{array}{c}\text { RLM X' } 2 \\
\text { dummy } \\
\text { años } \\
(8) \\
\end{array}$ & $\begin{array}{l}\text { RLM X' } \\
(9) \\
\end{array}$ & $\begin{array}{c}\text { RLM X' } 2 \\
(10) \\
\end{array}$ & $\begin{array}{c}\text { RLM X' } \\
\text { dummy } \\
\text { años } \\
(11)\end{array}$ & $\begin{array}{c}\text { RLM X' } 2 \\
\text { dummy } \\
\text { años } \\
(12)\end{array}$ \\
\hline LN(IPCFD) & $0,0947^{* * * *}$ & $-0,0305$ & $0,0978^{* * * *}$ & $-0,0263$ & $0,0847^{* * * *}$ & $-0,0332$ & $0,0919 * * *$ & $-0,0264$ & $0,1053 * * *$ & $-0,0371$ & $0,1135^{* * * *}$ & $-0,0282$ \\
\hline LN(IPCFD) CUADRADO & - & 0,0050 ** & - & $0,0050^{* * *}$ & - & $0,0048 * *$ & - & $0,0048^{*}$ & - & $0,0058^{*}$ & - & 0,0059 \\
\hline D10 & - & - & 0,0016 & 0,0015 & - & - & 0,0019 & 0,0019 & - & - & $-0,0025$ & $-0,0024$ \\
\hline D11 & - & - & $-0,0035$ & $-0,0035$ & - & - & $-0,0012$ & $-0,0012$ & - & - & $-0,0079$ & $-0,0079$ \\
\hline D12 & - & - & 0,0058 & 0,0058 & - & - & 0,0054 & 0,0055 & - & - & 0,0015 & 0,0013 \\
\hline D13 & - & - & 0,0001 & 0,0001 & - & - & $-0,0004$ & $-0,0002$ & - & - & $-0,0043$ & $-0,0048$ \\
\hline D14 & - & - & 0,0023 & 0,0021 & - & - & 0,0028 & 0,0028 & - & - & $-0,0013$ & $-0,0014$ \\
\hline D15 & - & - & $-0,0004$ & $-0,0001$ & - & - & 0,0003 & 0,0007 & - & - & $-0,0048$ & $-0,0040$ \\
\hline D16 & - & - & 0,0031 & 0,0033 & - & - & 0,0035 & 0,0039 & - & - & 0,0005 & 0,0012 \\
\hline PIM & - & - & - & - & $-0,0003$ & $-0,0002$ & $-0,0003$ & $-0,0002$ & - & - & - & - \\
\hline $\mathrm{PA}$ & - & - & - & - & - & - & - & - & $-0,0007$ & $-0,0007$ & $-0,0011$ & $-0,0011$ \\
\hline PM & - & - & - & - & - & - & - & - & 0,0004 & 0,0003 & 0,0000 & 0,0000 \\
\hline PCONST & - & - & - & - & - & - & - & - & 0,0000 & $-0,0002$ & $-0,0001$ & $-0,0004$ \\
\hline PCRH & - & - & - & - & - & - & - & - & 0,0030 & 0,0018 & 0,0077 & 0,0064 \\
\hline PSERV & - & - & - & - & - & - & - & - & 0,0006 & 0,0006 & $-0,0007$ & $-0,0006$ \\
\hline LN(INV) & - & - & - & - & - & - & - & - & 0,0037 & 0,0050 & 0,0079 & 0,0102 \\
\hline $\mathrm{CA}$ & - & - & - & - & $-0,0003^{*}$ & $-0,0003 *$ & $-0,0002$ & $-0,0002$ & $-0,0002$ & $-0,0002$ & $-0,0002$ & $-0,0002$ \\
\hline $\mathrm{AEB}$ & - & - & - & - & - & - & - & - & $-0,0007$ & $-0,0008$ & $-0,0007$ & $-0,0008$ \\
\hline AES & - & - & - & - & - & - & - & - & $-0,0004$ & $-0,0003$ & $-0,0004$ & $-0,0004$ \\
\hline PCES & - & - & - & - & 0,0006 & 0,0004 & 0,0002 & 0,0000 & 0,0004 & 0,0002 & 0,0000 & $-0,0002$ \\
\hline $\mathrm{PU}$ & - & - & - & - & $-0,0003$ & $-0,0001$ & $-0,0003$ & $-0,0002$ & $-0,0008$ & $-0,0006$ & $-0,0007$ & $-0,0006$ \\
\hline $\mathrm{EP}$ & - & - & - & - & - & - & - & - & $-0,0024$ & $-0,0024$ & $-0,0035$ & $-0,0035$ \\
\hline PCS & - & - & - & - & - & - & - & - & $-0,0009$ & $-0,0011$ & $-0,0008$ & $-0,0010$ \\
\hline TO & - & - & - & - & - & - & - & - & $-0,0007$ & $-0,0009$ & $-0,0009$ & $-0,0011$ \\
\hline TD & - & - & - & - & $-0,0002$ & $-0,0001$ & $-0,0002$ & $-0,0001$ & $-0,0003$ & $-0,0002997$ & $-0,0006$ & $-0,0006$ \\
\hline B $\quad$ (Intercepto) & $-0,0089$ ***** & $-0,0091^{* * * * *}$ & $-0,0102 * * *$ & $-0,0104 * * *$ & $-0,0092 * * * *$ & $-0,0093 * * *$ & $-0,0107 * *$ & $-0,0110^{* * *}$ & $-0,0078 * * *$ & $-0,0076 * * *$ & $-0,0054$ & $-0,0054$ \\
\hline $\mathrm{N}^{\circ}$ observaciones & 192 & 192 & 192 & 192 & 192 & 192 & 192 & 192 & 192 & 192 & 192 & 192 \\
\hline R Cuadrado & 0,1200 & 0,1364 & 0,1466 & 0,1629 & 0,1520 & 0,1667 & 0,1684 & 0,1834 & 0,1832 & 0,2037 & 0,2069 & 0,2275 \\
\hline Significancia global - p-valor & 0,0001 & 0,0001 & 0,0002 & 0,0001 & 0,0006 & 0,0003 & 0,0007 & 0,0003 & 0,0031 & 0,0017 & 0,0007 & 0,0004 \\
\hline
\end{tabular}

Nota 1: Las estimaciones presentan significancia de: $1 \%\left(^{(* *)}\right), 5 \%\left(^{* *}\right)$ y $10 \%\left(^{*}\right)$.

Nota 2: Los resultados de las estimaciones son robustos para evitar problemas de heterocedasticidad.

Fuente: Elaboración propia.

A partir de los resultados obtenidos con la implementación de las metodologías de MCO para datos de corte transversal y primera diferencia, se continúa con el enfoque para datos panel, buscando verificar o descartar robustez en la relación entre niveles de ingreso y de desigualdad.

Como se mostró previamente, al tener disponibles pocos años de referencia en el periodo 2002-2005, las estimaciones no son consistentes y los coeficientes no son significativos. Esto se observa en todas las metodologías implementadas, y en el caso de la estimación para datos panel se presentan en los Anexo 4, Anexo 5, Anexo 6 y Anexo 8. Al tener pocos años de observación, se tiene disponible una muestra muy pequeña (52 observaciones), por lo que en la especificación 2 no se puede estimar el estadístico $\mathrm{F}$, por los bajos grados de libertad, problema conocido como micronumerosidad (Wooldridge, 2013).

En la estimación presentada en la Tabla 5, se observa que no hay relación estadísticamente significativa entre la desigualdad medida por el coeficiente de Gini y los niveles de ingreso, y de hecho, solamente son significativas PCES, PCS y EP para algunas de las estimaciones. En la estimación de efectos fijos con variable dependiente índice de Theil, se encuentra una relación en forma de "U" significativa para la especificación 1, y no significativa para la 2 (Anexo 7). 
TABLA 5.

Estimaciones de efectos fijos con datos panel sobre el coeficiente de Gini 2008-2016

\begin{tabular}{|c|c|c|c|c|c|c|}
\hline \multirow[b]{2}{*}{ Variables independientes } & \multicolumn{3}{|c|}{ 1a especificación } & \multicolumn{3}{|c|}{$2^{\text {a }}$ especificación } \\
\hline & $\begin{array}{c}\text { Efectos fijos } \mathrm{X}^{\prime} \\
(1) \\
\end{array}$ & $\begin{array}{c}\text { Efectos fijos } \\
\mathrm{X}^{\prime} 2 \\
(2) \\
\end{array}$ & $\begin{array}{c}\text { Efectos fijos } X^{\prime} \\
\text { LN(IPCFD) año } \\
(3)\end{array}$ & $\begin{array}{c}\text { Efectos fijos } \\
\mathrm{X}^{\prime} \\
(4) \\
\end{array}$ & $\begin{array}{c}\text { Efectos fijos } \\
\mathrm{X}^{\prime} 2 \\
(5) \\
\end{array}$ & $\begin{array}{c}\text { Efectos fijos } X^{\prime} \\
\text { LN(IPCFD) año } \\
(6)\end{array}$ \\
\hline $\mathrm{LN}(\mathrm{IPCFD})$ & $-0,0368$ & $-0,9366$ & - & 0,0465 & $-0,6689$ & - \\
\hline LN(IPCFD) CUADRADO & - & 0,0350 & - & - & 0,0277 & - \\
\hline LN(IPCFD) 09 & - & - & $-0,0004$ & - & - & 0,0002 \\
\hline LN(IPCFD) 10 & - & - & $-0,0007 * *$ & - & - & 0,0002 \\
\hline LN(IPCFD) 11 & - & - & $-0,0015 * * *$ & - & - & $-0,0003$ \\
\hline $\mathrm{LN}(\mathrm{IPCFD}) 12$ & - & - & $-0,0017 * * *$ & - & - & $-0,0003$ \\
\hline LN(IPCFD) 13 & - & - & $-0,0023 * * *$ & - & - & $-0,0007$ \\
\hline LN(IPCFD) 14 & - & - & $-0,0026^{* * *}$ & - & - & $-0,0007$ \\
\hline LN(IPCFD) 15 & - & - & $-0,0035 * * *$ & - & - & $-0,0013$ \\
\hline LN(IPCFD) 16 & - & - & $-0,0041 * * *$ & - & - & $-0,0017$ \\
\hline PIM & 0,0017 & $0,0023 *$ & $-0,0007$ & - & - & - \\
\hline PA & - & - & - & 0,0028 & 0,0020 & 0,0026 \\
\hline $\mathrm{PM}$ & - & - & - & 0,0005 & $-0,0001$ & 0,0005 \\
\hline PCONST & - & - & - & $-0,0009$ & $-0,0013$ & $-0,0003$ \\
\hline PCRH & - & - & - & $-0,0048$ & $-0,0062$ & $-0,0011$ \\
\hline PSERV & - & - & - & 0,0016 & 0,0013 & 0,0005 \\
\hline LN(INV) & - & - & - & $-0,0003$ & $-0,0014$ & 0,0027 \\
\hline $\mathrm{CA}$ & $-0,0001$ & $-0,0001$ & 0,0000 & 0,0000 & $-0,0001$ & 0,0000 \\
\hline AEB & - & - & - & $-0,0004$ & $-0,0004$ & $-0,0002$ \\
\hline AES & - & - & - & 0,0003 & 0,0001 & $-0,0001$ \\
\hline PCES & $-0,0032 * *$ & $-0,0033 * *$ & 0,0011 & $-0,0008$ & $-0,0008$ & 0,0014 \\
\hline $\mathrm{PU}$ & $-0,0008$ & $-0,0010$ & $-0,0004$ & $-0,0006$ & $-0,0007$ & $-0,0004$ \\
\hline EP & - & - & - & $-0,0145 * * *$ & $-0,0149 * * *$ & $-0,0089$ \\
\hline PCS & - & - & - & $-0,0014 * *$ & $-0,0013 * *$ & $-0,0011 *$ \\
\hline TO & - & - & - & $-0,0007$ & $-0,0007$ & $-0,0004$ \\
\hline TD & 0,0002 & 0,0000 & $-0,0003$ & $-0,0007$ & $-0,0008$ & $-0,0010$ \\
\hline$\beta$ (Intercepto) & $1,0790^{* * *}$ & 6,8642 & $0,5569 * * *$ & 0,5562 & 5,2414 & $0,8859 * *$ \\
\hline Sigma_u & 0,0423 & 0,0420 & 0,0287 & 0,0458 & 0,0440 & 0,0356 \\
\hline Sigma_e & 0,0172 & 0,0171 & 0,0154 & 0,0151 & 0,0151 & 0,0151 \\
\hline $\mathrm{N}^{\circ}$ observaciones & 216 & 216 & 216 & 216 & 216 & 216 \\
\hline R Cuadrado & 0,0457 & 0,0369 & 0,3100 & 0,1510 & 0,1543 & 0,2087 \\
\hline Significancia global - p-valor & 0,0000 & 0,0000 & 0,0000 & 0,0000 & 0,0000 & 0,0000 \\
\hline
\end{tabular}

Nota 1: Las estimaciones presentan significancia de: $1 \%\left(^{* * *}\right), 5 \%\left(^{* *}\right)$ y $10 \%\left(^{*}\right)$.

Nota 2: Los resultados de las estimaciones son robustos para evitar problemas de heterocedasticidad.

Fuente: Elaboración propia.

Al considerar el efecto interacción entre los años y $L N(I P C F D)$ en la especificación 1 (columna 3) se encontraron estimadores estadísticamente significativos, indicando que un cambio secular en la reducción de los niveles de desigualdad han estado asociados a aumentos en los niveles de ingreso, sin embargo, ese resultado no es significativo en la especificación 2 (columna 6).

De acuerdo con los resultados de la estimación por efectos aleatorios para el periodo 2008-2016, considerando el coeficiente de Gini (Tabla 6) y el índice de Theil (Anexo 9) se encontró que la relación entre el $L N(I P C F D)$ y los indicadores de desigualdad es negativa en la especificación 1 (lineal) y estadísticamente significativa para el Gini, además, cuando se incorpora la forma cuadrática del $L N(I P C F D)$ se evidencia la relación de "U” en ambas especificaciones, aunque solo es significativa para el Theil (Anexo 9). 
TABLA 6.

Estimaciones de efectos aleatorios con datos panel sobre el coeficiente de Gini 2008-2016

\begin{tabular}{|c|c|c|c|c|c|c|}
\hline \multirow[b]{2}{*}{ Variables independientes } & \multicolumn{3}{|c|}{$1^{a}$ especificación } & \multicolumn{3}{|c|}{ 2a especificación } \\
\hline & $\begin{array}{c}\text { Efectos } \\
\text { aleatorios } X^{\prime} \\
(1) \\
\end{array}$ & $\begin{array}{c}\text { Efectos } \\
\text { aleatorios } X^{\prime} 2 \\
(2) \\
\end{array}$ & $\begin{array}{c}\text { Efectos } \\
\text { aleatorios } X^{\prime} \\
\text { LN(IPCFD) año } \\
(3) \\
\end{array}$ & $\begin{array}{c}\text { Efectos } \\
\text { aleatorios } X^{\prime} \\
(4) \\
\end{array}$ & $\begin{array}{c}\text { Efectos } \\
\text { aleatorios X } \\
\text { (5) }\end{array}$ & $\begin{array}{c}\text { Efectos } \\
\text { aleatorios } X^{\prime} \\
\text { LN(IPCFD) año } \\
(6)\end{array}$ \\
\hline $\mathrm{LN}(\mathrm{IPCFD})$ & $-0,0469^{* *}$ & $-1,1210$ & - & 0,0417 & $-0,6782$ & - \\
\hline LN(IPCFD) CUADRADO & - & 0,0416 & - & - & 0,0278 & - \\
\hline LN(IPCFD) 09 & - & - & $-0,0004 * *$ & - & - & $-0,0008$ \\
\hline LN(IPCFD) 10 & - & - & $-0,0008 * * *$ & - & - & $-0,0012 *$ \\
\hline LN(IPCFD) 11 & - & - & $-0,0016^{* * *}$ & - & - & $-0,0022 * *$ \\
\hline LN(IPCFD) 12 & - & - & $-0,0018 * * *$ & - & - & $-0,0029 * * *$ \\
\hline LN(IPCFD) 13 & - & - & $-0,0025 * * *$ & - & - & $-0,0048 * * *$ \\
\hline LN(IPCFD) 14 & - & - & $-0,0028 * * *$ & - & - & $-0,0055^{* * *}$ \\
\hline LN(IPCFD) 15 & - & - & $-0,0037 * * *$ & - & - & $-0,0063 * * *$ \\
\hline LN(IPCFD) 16 & - & - & $-0,0044 * * *$ & - & - & $-0,0069 * * *$ \\
\hline PIM & 0,0007 & 0,0009 & $-0,0010$ & - & - & - \\
\hline PA & - & - & - & 0,0003 & 0,0000 & $0,0026^{* *}$ \\
\hline PM & - & - & - & $-0,0007$ & $-0,0009$ & $0,0027 * * *$ \\
\hline PCONST & - & - & - & $-0,0013$ & $-0,0015$ & $0,0054 * * *$ \\
\hline PCRH & - & - & - & $-0,0020$ & $-0,0025$ & $-0,0013$ \\
\hline PSERV & - & - & - & 0,0000 & $-0,0003$ & $0,0033^{* * *}$ \\
\hline LN(INV) & - & - & - & $-0,0026$ & $-0,0037$ & $0,0280 * *$ \\
\hline $\mathrm{CA}$ & 0,0001 & 0,0000 & 0,0000 & 0,0000 & $-0,0001$ & 0,0002 \\
\hline AEB & - & - & - & $-0,0006$ & $-0,0004$ & 0,0024 \\
\hline AES & - & - & - & 0,0006 & 0,0003 & 0,0007 \\
\hline PCES & $-0,0021 * *$ &,$- 0024436 * *$ &, $0018059 *$ & $-0,0007$ & $-0,0008$ & $0,0039 * *$ \\
\hline $\mathrm{PU}$ & 0,0001 & $-0,00006$ & $-0,0010^{*}$ & $-0,0006$ & $-0,0006$ & $-0,0023 * * *$ \\
\hline $\mathrm{EP}$ & - & - & - & $-0,0107 * * *$ & $-0,0114 * * *$ & $0,0059^{*}$ \\
\hline PCS & - & - & - & $-0,0015 * * *$ & $-0,0014 * *$ & $-0,0009$ \\
\hline TO & - & - & - & $-0,0006$ & $-0,0005$ & $-0,00225^{*}$ \\
\hline TD & 0,0010 & 0,0006 & $-0,0002$ & 0,0001 & $-0,0001$ & 0,0005 \\
\hline$\beta$ (Intercepto) & $1,1248 * * *$ & $8,0798^{*}$ & $0,5910 * * *$ & 0,5965 & 5,2964 & $-0,0100$ \\
\hline Sigma_u & 0,0267 & 0,0276 & 0,0281 & 0,0268 & 0,0286 & 0,0000 \\
\hline Sigma_e & 0,0172 & 0,0171 & 0,0154 & 0,0151 & 0,0151 & 0,0387 \\
\hline $\mathrm{N}^{\circ}$ observaciones & 216 & 216 & 216 & 216 & 216 & 216 \\
\hline R Cuadrado & 0,0788 & 0,1120 & 0,3863 & 0,1518 & 0,1529 & 0,5928 \\
\hline Significancia global - p-valor & 0,0000 & 0,0000 & 0,0000 & 0,0000 & 0,0000 & 0,0000 \\
\hline
\end{tabular}

Nota 1: Las estimaciones presentan significancia de: $\left.1 \%\left(^{* * *}\right), 5 \%{ }^{(* *}\right)$ y $10 \%\left(^{*}\right)$.

Nota 2: Los resultados de las estimaciones son robustos para evitar problemas de heterocedasticidad.

Fuente: Elaboración propia.

En cuanto a la variable de interacción años por $L N(I P C F D)$ se evidenció que la relación es negativa y significativa tanto para la especificación 1 y 2 , en el que se obtuvo resultados parecidos a la técnica de efectos fijos (exceptuando la especificación 2 que no fue estadísticamente significativa), reflejando que cambios positivos en los niveles de ingreso puede estar vinculado con reducciones en la desigualdad. Igualmente, en las variables PCS y PCES presentaron un efecto negativo sobre el coeficiente de Gini y el índice de Theil, por lo que un aumento en el acceso de las personas a las instituciones puede generar efectos redistributivos positivos.

En síntesis, se puede concluir que con las técnicas de estimación econométrica para datos panel, no se encuentra un vínculo preciso en la relación entre niveles de ingreso por departamento y su desigualdad. El coeficiente estimado es significativo para dos 
de las estimaciones de 2002-2005, y para 5 de las 16 estimaciones de 2008-2016. En la Tabla 7 se sintetizan todas las formas funcionales de todos los modelos estimados para datos panel, su significatividad estadística, y el test de Hausman, a partir de este se establece cual es el mejor método de estimación en cada especificación, periodo considerado, e indicador de desigualdad.

TABLA 7.

Formas funcionales de las estimaciones de efectos fijos y aleatorios para los indicadores de desigualdad

\begin{tabular}{|c|c|c|c|c|c|}
\hline \multirow{4}{*}{ Especificaciones } & \multirow{4}{*}{ Metodología con datos panel } & \multicolumn{4}{|c|}{ Periodos de referencia } \\
\hline & & \multicolumn{2}{|c|}{$2002-2005$} & \multicolumn{2}{|c|}{ 2008-2016 } \\
\hline & & & Indicadores & desigualdad & \\
\hline & & Gini & Theil & Gini & Theil \\
\hline \multirow{5}{*}{ Estimación $X^{\prime}(1)$} & Efectos fijos & & & & \\
\hline & Significancia & & & & \\
\hline & Efectos aleatorios & & & & \\
\hline & Significancia & & & ** & \\
\hline & Test Hausman & 0,7045 (No se rechaza) & 0,5863 (No se rechaza) & 0,0028 (se rechaza) & 0.0006 (se rechaza) \\
\hline \multirow{5}{*}{ Estimación $X^{\prime} 2$ (2) } & Efectos fijos & & & U & $U$ \\
\hline & Significancia & & & & * \\
\hline & Efectos aleatorios & $U$ & $U$ & $\mathrm{U}$ & U \\
\hline & Significancia & $* *$ & & & ** \\
\hline & Test Hausman & 0,9444 (No se rechaza ) & 0,8584 (No se rechaza) & 0,0096 (se rechaza) & 0.0020 (se rechaza) \\
\hline \multirow{4}{*}{ Estimación X' (4) } & Efectos fijos & & & & \\
\hline & Significancia & & * & & ** \\
\hline & Efectos aleatorios & & & & \\
\hline & $\begin{array}{l}\text { Significancia } \\
\text { Test Hausman }\end{array}$ & 0,0249 (No se rechaza) & 0,0054 (Se rechaza) & 0,9850 (No se rechaza) & 0.9892 (No se rechaza) \\
\hline \multirow{5}{*}{ Estimación X' (5) } & Efectos fijos & & & & \\
\hline & Significancia & & & & \\
\hline & Efectos aleatorios & $U$ & & & \\
\hline & Significancia & & & & * \\
\hline & Test Hausman & $\begin{array}{l}\text { No se estima por bajos } \\
\text { grados de libertad }\end{array}$ & $\begin{array}{l}\text { No se estima por bajos } \\
\text { grados de libertad }\end{array}$ & 0.8983 (No se rechaza) & 0.9403 (No se rechaza) \\
\hline
\end{tabular}

Nota 1: El test de Hausman se rechaza si el p-valor es menor 0,05 se prefiere efectos fijos a efectos aleatorios para evitar sesgos.

Nota 2: Las estimaciones presentan significancia de: $5 \%\left(^{* *}\right)$ y $10 \%\left(^{*}\right)$.

Fuente: Elaboración propia.

El resultado principal es que no hay robustez en la asociación de los niveles de ingreso y su desigualdad, por lo que hay que tener cautela a la hora de interpretar los resultados cuando se toma en consideración una única especificación. En el modelo reducido la relación es inversa (aunque no estadísticamente significativa) para ambos periodos en el modelo de efectos fijos, mientras que en la estimación por efectos aleatorios es positiva para 2002-2005, y negativa en 2008-2016. En la versión ampliada (controlando por más covariables) la relación es positiva, más ingreso estaría asociado a mayores niveles de desigualdad, en el periodo 2008-2016 independientemente de la técnica utilizada, mismo resultado para 2002-2005 en la estimación por efectos aleatorios. 
Cuando se considera una relación cuadrática en el logaritmo del ingreso per cápita por departamento, la forma de la relación tiene más consistencia para el periodo 2008-2016, independientemente del método de estimación, aunque cambia levemente dependiendo de la especificación. En las estimaciones para el periodo 2008-2016, en la versión reducida se encuentra una forma de "U" en la relación entre nivel de ingreso y desigualdad, mientras que en la versión ampliada hay una relación positiva y marginalmente creciente, a partir de estos resultados se descartaría la "U invertida" de Kuznets.

$\mathrm{Al}$ estimar el test de Hausman, se encuentran resultados consistentes, debido a que la consideración sobre el modelo más adecuado es independiente del indicador de desigualdad (salvo en la estimación para 2002-2005 en la forma lineal en el modelo ampliado). Para la estimación sintética (cinco variables de control) en todas las especificaciones, para ambos indicadores de desigualdad, se tienen resultados diferentes según el periodo considerado: mientras que para 2002-2005 no se rechaza la hipótesis nula de correlación con los inobservables, y por lo tanto, se prefiere la estimación por efectos aleatorios, en la estimación para el periodo reciente (2008-2016) se rechaza la hipótesis nula que indica que los coeficientes por el método de efectos fijos son consistentes y los de efectos aleatorios son eficientes y consistentes, concluyendo que se prefiere la estimación de efectos fijos, porque la estimación por MCG no es consistente.

Para la especificación completa (todas las covariables presentadas en la Tabla 1) para 2008-2016, no se rechaza la hipótesis nula y se prefiere la estimación por efectos aleatorios por su eficiencia ${ }^{16}$. Este último resultado se explica porque al incluir más variables independientes se reduce la probabilidad de que las variables omitidas estén correlacionadas con las variables incluidas en las estimaciones, por lo tanto, en el modelo ampliado se concluye que esa correlación existe y se prefiere la estimación por efectos aleatorios al ser más eficiente.

A partir de las estimaciones planteadas a lo largo de esta sección se observa que los resultados de la relación entre la desigualdad y los niveles de ingreso, y su significatividad estadística dependen de la metodología planteada, la especificación y el periodo considerado, por lo que hay que tomar con cautela interpretaciones definitivas sobre su relación.

En el caso de las estimaciones para datos panel para el periodo 2002-2005 no hay consistencia, en parte por el tamaño de la muestra; mientras que para 20082016 los resultados no cambian al estimar por efectos fijos o aleatorios ni en la especificación cuadrática, y es independiente del indicador de desigualdad considerado; pero los resultados sí cambian en función de la especificación y el número de covariables de control. Además, con estas metodologías para datos panel, no hay significatividad estadística en la mayoría de parámetros estimados de la relación entre nivel de ingreso y desigualdad, indicando que, como se ha resaltado en otros estudios, hay factores considerados (como los cambios demográficos y los

${ }^{16}$ Hay que resaltar que en el modelo ampliado para el periodo 2002-2005 no se estima el test de Hausman al tener una muestra pequeña que hace imposible estimar el estadístico Chi-cuadrado por los bajos grados de libertad. 
niveles de escolaridad) y otros no considerados en esta indagación, que tendrían un rol fundamental en explicar las diferencias y los cambios en la desigualdad del ingreso.

\section{Conclusiones}

En los últimos años el tema de la desigualdad ha sido de los más preocupantes en todos los países del mundo, buscando analizar esa problemática diferentes estudios empíricos han intentado comprender la importancia de los niveles de la desigualdad, sus factores asociados, y así tener un adecuado diagnóstico para generar estrategias de política que propendan por su reducción.

A partir de los resultados obtenidos con la evidencia empírica de la relación entre niveles de ingreso y desigualdad para Colombia aportados en este artículo, se encontró que la complejidad del fenómeno de estudio y las limitaciones en términos de información indican que en Colombia a nivel departamental los resultados hay que tomarlos con cautela, dado que los resultados cambian según la metodología y las especificaciones estimadas.

De este modo, hay que destacar la existencia de múltiples factores que están articulados a los niveles de desigualdad, y esto se refleja en los cambios presentados en las estimaciones cuando se considera el logaritmo del ingreso per cápita promedio por departamentos y sus respectivos coeficientes de Gini, encontrando que hay otras variables que inciden en la inequidad, y que ésta no tiene una relación claramente definida con los niveles de ingreso y desarrollo. La desigualdad es el resultado de una multiplicidad de factores históricos, sociales, culturales y estructurales, por ello las limitaciones a la hora de estimar cuantitativamente sus determinantes (Bourguignon \& Morrison, 1998).

Un aspecto a destacar, es que a pesar de los cambios en la relación según la metodología implementada y la especificación del modelo, se mantienen los mismos resultados independientemente del indicador de desigualdad utilizado. Mostrando que la falta de robustez se deriva de aspectos metodológicos y de estimación, y no de la forma en que se mide la desigualdad (al menos con los dos indicadores utilizados en este trabajo).

En Colombia los niveles de desigualdad se han sostenido, incluso aunque se presentaron importantes reducciones en la pobreza y un aceptable nivel de crecimiento económico. Por lo anterior, se recomienda realizar políticas que busquen reducir las brechas de desigualdad de ingreso entre departamentos a partir de políticas redistributivas, pero simultáneamente se debe fomentar, con foco en los departamentos con mayores problemáticas de ingreso y desigualdad, el mejoramiento en los niveles de educación, mayor inversión en infraestructura, fortalecimiento y credibilidad de la instituciones, movilidad entre grupos sociales, mayor acceso a los servicios públicos domiciliarios y mejoramiento de las condiciones y oportunidades en el mercado laboral. 


\section{REFERENCIAS}

Acemoglu, D. \& Robinson, J. (2012). Why Nations Fail: The Origins of Power, Prosperity, and Poverty. New York: Crow Publishing Group.

Argüello, R. (2006). Revisiting the Relationship between Income Inequality and Economic Growth. Lecturas de Economia, 64, 37-58.

Atkinson, A. (2015). Inequality: what can be done? Cambridge: Harvard University Press.

Azzoni, C. (2001). Economic growth and regional income inequality in Brazil. The Annals of Regional Science, 35(1), 133-152.

Barón, J. (2003). ¿Qué sucedió con las disparidades económicas regionales en Colombia 1980 y el 2000? [Serie Documentos de Trabajo sobre Economía Regional y Urbana No. 38]. Recuperado de http://www.banrep.gov.co/sites/default/ files/publicaciones/archivos/DTSER38-Disparidades.pdf

Bonilla, L. (2011). Diferencias regionales en la distribución del ingreso en Colombia. Sociedad y Economía, 21, 43-68.

Bourguignon, F., Ferreira, F. \& Menéndez, M. (2007). Inequality of opportunity in Brazil. Review of Income and Wealth, 53(4), 585-618.

Bourguignon, F. \& Morrison, C. (1998). Inequality and development: the role of dualism. Journal of Development Economics, 57(2), 233-257.

Casas, J. (2017). Implicaciones de los acuerdos del Fondo Monetario Internacional sobre la pobreza en Colombia. Económicas CUC, 38(1), 9-36. https://oi. org/10.17981/econcuc.38.1.01

Chumaceiro, A. (2013). Políticas internacionales, nacionales y políticas públicas tributarias en Venezuela como promotoras de la responsabilidad social de las empresas. [Tesis de Grado]. Universidad Dr. Rafael Belloso Chacín, Maracaibo Venezuela.

Cowell, F. (2011). Measuring Inequality. New York: Oxford University Press.

Deininger, K. \& Squire, L. (1998). New ways of looking at old issues: inequality and growth. Journal of Development Economics, 57(2), 259-287.

Gallo, M., Garrido, R., Gonzáles, E. y Pozo, J. (2015). La cara amarga del crecimiento económico peruano: persistencia de la desigualdad y divergencia territorial. [Documentos de trabajo No. 75]. Madrid: IELAT.

Galvis, L. y Meisel, A. (2010). Persistencia de las desigualdades regionales en Colombia: Un análisis espacial. [Serie Documentos de Trabajo sobre Economía Regional y Urbana No. 120]. Recuperado de http://www.banrep.gov.co/sites/default/files/publicaciones/archivos/DTSER-120.pdf

García, J. (2015). Los retos del presente en la economía colombiana. En, H. Castaño, J. García, C. Posada, C. Ruiz y J. Guzmán. Economía Colombiana Análisis de Coyuntura, (pp. 1-24). Medellín: CIEF.

Gaviria, M. (2005). Distribución del ingreso y crecimiento económico. Economía y Desarrollo, 4(2), 110-128. 
González, R., Galeano, H. y Trejos, L. (2015). Estados Unidos en la política exterior colombiana: ¿aliado incondicional? Económicas CUC, 36(1), 43-56. Recuperado a partir de https://revistascientificas.cuc.edu.co/economicascuc/article/ view/672

Greene, W. (2003). Econometric analysis. New Jersey: Pearson education.

Hausman, J. (1978). Specification test in econometrics. The Journal of the Econometric Society, 46(6), 1251-1271.

Hernández, J. y Chumaceiro, A. (2018). Acercamiento histórico a la participación ciudadana en Venezuela: Modelo de relación Estado-Sociedad (19582012). RCS, 24(2), 56-67. Disponible en https://dialnet.unirioja.es/servlet/ articulo?codigo $=7024300$

Herzer, D. \& Vollmer, S. (2012). Inequality and growth: evidence from panel cointegration. The Journal of Economic Inequality, 10(4), 489-503.

Kuznets, S. (1955). Economic growth and income inequality. American Economic Review, 45(1), 2-28.

Piketty, T. (2014). El Capital en el siglo XXI. México D.F.: Fondo de Cultura Económica.

Ray, D. (2002). La economía del desarrollo. Barcelona: Antoni Bosch.

República de Colombia. DANE. (2017a). Microdatos anonimizados: Encuesta continua de hogares. [Gran encuesta integrada de hogares]. Recuperado de www. dane.gov.co

República de Colombia. DANE. (2017b). Cuentas nacionales-2002-2016. [Online]. Recuperado de www.dane.gov.co

República de Colombia. DNP. (2017). Inversión regional 2002-2016. [Online]. Recuperado de www.dnp.gov.co

Rodrik, D. (2011). Una economía, Muchas recetas. La globalización, las instituciones y el crecimiento económico. México D.F.: FCE.

Sánchez, R. (2017). Desigualdad del ingreso en Colombia: un estudio por departamentos. Cuadernos de Economía, 36(72), 139-178.

Stiglitz, J. (2012). El precio de la desigualdad. El 1\% de la población tiene lo que el 99\% necesita. Madrid: Santillana.

The World Bank. (2017). Datos Banco Mundial. [Online]. Recuperado de http://datos.bancomundial.org/indicador/SI.POV.GINI

Wooldridge, J. (2013). Introducción a la econometría. México D. F.: Cengage Learning.

Zúñiga, J. (2017). De la función económica del cheque, del cheque común al de pago diferido. Jurídicas CUC, 13(1), 183-198. https://doi.org/10.17981/juridcuc.13.1.2017.08 


\section{BIODATA}

Roberto Mauricio Sánchez Torres es profesor e investigador de la Universidad Nacional (Colombia) y la Universidad de La Salle (Colombia). Magíster en Economía de la Universidad Nacional de La Plata (Argentina) y Magíster en Ciencias Sociales de la Universidad de Buenos Aires (Argentina). https://orcid.org/0000-0001-6684-8707

Luis Alejandro Ramirez Nariño es integrante del Grupo del Semillero de Investigación en Estudios del Trabajo y Economista de la Universidad de La Salle. https://orcid. org/0000-0002-8555-9772

Luis Felipe Torres Méndez es integrante del Grupo del Semillero de Investigación en Estudios del Trabajo. Economista de la Universidad de La Salle y Especialista en Gerencia Financiera de la Universidad Sergio Arboleda (Colombia). https://orcid.org/0000-00023676-7727 
Anexos

Anexo 1.

Indicadores educativos por departamento 2008 - 2016

\begin{tabular}{|c|c|c|c|c|c|c|c|c|c|c|}
\hline \multirow[b]{2}{*}{ Departamento } & \multicolumn{5}{|c|}{2008} & \multicolumn{5}{|c|}{2016} \\
\hline & $\begin{array}{c}\text { \% Personas } \\
\text { con educación } \\
\text { superior.1 }\end{array}$ & $\begin{array}{l}\text { Asistencia a } \\
\text { educación } \\
\text { básica. } 2\end{array}$ & $\begin{array}{c}\text { Asistencia a } \\
\text { educación } \\
\text { superior.3 }\end{array}$ & $\begin{array}{l}\text { Años Promedio } \\
\text { de escolaridad. } 4\end{array}$ & Analfabetismo & $\begin{array}{l}\% \text { Personas } \\
\text { con educación } \\
\text { superior.1 }\end{array}$ & $\begin{array}{c}\text { Asistencia a } \\
\text { educación } \\
\text { básica.2 }\end{array}$ & $\begin{array}{c}\text { Asistencia a } \\
\text { educación } \\
\text { superior.3 }\end{array}$ & $\begin{array}{c}\text { Años Promedio } \\
\text { de escolaridad.4 }\end{array}$ & Analfabetismo \\
\hline Antioquia & 18,72 & 88,35 & 38,68 & 7,82 & 11,91 & 25,62 & 92,99 & 40,08 & 8,58 & 10,25 \\
\hline Atlántico & 20,47 & 91,76 & 36,64 & 8,70 & 10,91 & 24,57 & 93,96 & 32,60 & 9,14 & 10,55 \\
\hline Bogotá D.C. & 32,71 & 93,85 & 43,52 & 9,93 & 6,51 & 34,01 & 96,05 & 41,54 & 10,30 & 6,16 \\
\hline Bolívar & 16,23 & 93,44 & 42,20 & 7,02 & 16,53 & 22,65 & 93,48 & 34,56 & 8,08 & 14,00 \\
\hline Boyacá & 13,92 & 91,89 & 43,08 & 6,55 & 12,15 & 20,81 & 96,70 & 44,57 & 7,89 & 10,07 \\
\hline Caldas & 11,81 & 86,93 & 40,43 & 6,42 & 12,16 & 17,81 & 92,10 & 34,61 & 7,61 & 9,66 \\
\hline Caquetá & 6,99 & 87,04 & 33,27 & 5,25 & 16,48 & 13,79 & 89,36 & 30,74 & 6,43 & 15,58 \\
\hline Cauca & 10,61 & 87,84 & 40,89 & 5,67 & 13,85 & 18,08 & 92,99 & 37,92 & 7,11 & 12,29 \\
\hline Cesar & 12,25 & 89,09 & 43,37 & 6,55 & 18,26 & 20,25 & 91,84 & 37,52 & 7,55 & 17,15 \\
\hline Córdoba & 10,37 & 92,82 & 35,89 & 6,39 & 20,28 & 19,99 & 94,60 & 33,76 & 7,91 & 26,83 \\
\hline Cundinamarca & 11,57 & 91,58 & 32,01 & 6,44 & 10,87 & 15,28 & 92,63 & 31,66 & 6,23 & 16,44 \\
\hline Chocó & 8,74 & 90,11 & 43,90 & 5,09 & 26,41 & 17,86 & 95,84 & 37,73 & 7,28 & 9,86 \\
\hline Huila & 10,57 & 86,15 & 37,02 & 6,10 & 14,43 & 19,09 & 91,69 & 37,33 & 7,44 & 10,91 \\
\hline La Guajira & 15,56 & 87,71 & 41,74 & 6,85 & 20,43 & 25,13 & 92,77 & 33,79 & 7,57 & 19,52 \\
\hline Magdalena & 12,30 & 91,68 & 33,89 & 6,45 & 18,11 & 15,24 & 93,90 & 27,28 & 7,53 & 16,74 \\
\hline Meta & 11,70 & 88,58 & 27,49 & 6,90 & 13,23 & 14,30 & 91,84 & 30,35 & 7,66 & 11,29 \\
\hline Nariño & 12,58 & 92,79 & 31,89 & 6,36 & 15,14 & 16,26 & 94,46 & 27,58 & 6,83 & 12,89 \\
\hline Norte de Santander & 12,09 & 90,52 & 34,07 & 6,63 & 14,42 & 15,74 & 90,74 & 40,51 & 7,10 & 12,44 \\
\hline Quindío & 15,11 & 90,68 & 39,97 & 7,75 & 11,62 & 17,63 & 92,54 & 34,97 & 7,68 & 10,90 \\
\hline Risaralda & 13,46 & 88,38 & 36,40 & 6,93 & 11,64 & 17,40 & 93,07 & 35,93 & 7,78 & 9,11 \\
\hline Santander & 16,76 & 91,52 & 42,76 & 7,36 & 9,99 & 22,42 & 93,85 & 37,23 & 8,22 & 9,26 \\
\hline Sucre & 11,72 & 91,57 & 41,17 & 5,92 & 21,73 & 16,47 & 94,80 & 33,99 & 6,82 & 19,89 \\
\hline Tolima & 12,14 & 88,28 & 39,68 & 6,43 & 13,31 & 16,00 & 91,71 & 36,60 & 7,25 & 11,24 \\
\hline Valle del Cauca & 16,15 & 90,68 & 30,43 & 7,77 & 10,90 & 19,82 & 93,39 & 30,10 & 8,57 & 10,05 \\
\hline Total Nacional & 17,87 & 90,65 & 38,31 & 7,54 & 12,42 & 22,77 & 93,68 & 36,55 & 8,35 & 10,51 \\
\hline
\end{tabular}

Nota 1: Las personas con educación superior contempla la población mayor a 26 años de edad.

Nota 2: La asistencia a educación básica contempla la población entre 5 y 16 años de edad.

Nota 3: La asistencia a educación superior contempla la población entre 17 y 26 años de edad.

Nota 4: La edad promedio contempla la población mayor a 26 años de edad.

Nota 5: Se tomó como referencia el periodo 2008-2016 por falta de comparabilidad entre la ECH y la GEIH.

Fuente: Elaboración propia con base en DANE (2017a). 
Anexo 2.

Estimaciones MCO sobre el coeficiente de Gini por departamento 2002-2005

\begin{tabular}{|c|c|c|c|c|c|c|c|c|c|c|c|c|}
\hline \multirow[b]{2}{*}{ Variables independientes } & \multicolumn{4}{|c|}{$1^{a}$ especificación } & \multicolumn{4}{|c|}{ 2a especificación } & \multicolumn{4}{|c|}{$3^{a}$ especificación } \\
\hline & $\begin{array}{l}\text { RLS } \\
\text { (1) }\end{array}$ & $\begin{array}{c}\text { RLS2 } \\
\text { (2) }\end{array}$ & $\begin{array}{c}\text { RLS } \\
\text { dummy } \\
\text { año } \\
\text { (3) }\end{array}$ & $\begin{array}{c}\text { RLS } 2 \\
\text { dummy } \\
\text { año } \\
\text { (4) }\end{array}$ & RLM X' & $\begin{array}{c}\text { RLM X' } 2 \\
(6)\end{array}$ & $\begin{array}{c}\text { RLM X' } \\
\text { dummy } \\
\text { años } \\
\text { (7) }\end{array}$ & $\begin{array}{c}\text { RLM X' } 2 \\
\text { dummy } \\
\text { años } \\
\text { (8) }\end{array}$ & RLM X' & RLM X' 2 & $\begin{array}{c}\text { RLM X' } \\
\text { dummy } \\
\text { años } \\
(11)\end{array}$ & $\begin{array}{c}\text { RLM X' } 2 \\
\text { dummy } \\
\text { años } \\
\text { (12) }\end{array}$ \\
\hline $\mathrm{LN}(\mathrm{IPCFD})$ & $0,0390 * * *$ & $-2,0553 * * * 0$ & $0,0405^{* * *}$ & $-2,0066^{* *}$ & 0,0257 & $-1,7749 * *$ & 0,0237 & $-1,6262 * *$ & 0,0649 & $-0,3965$ & 0,0396 & 1,0735 \\
\hline LN(IPCFD) CUADRADO & - & $0,0810 * * *$ & - & $0,0791 * *$ & - & $0,0699 * *$ & - & $0,0641 * *$ & - & 0,0177 & - & $-0,0401$ \\
\hline D03 & - & - & $-0,0041$ & $-0,0026$ & - & - & $-0,0037$ & $-0,0014$ & - & - & $-0,0079$ & $-0,0124$ \\
\hline D04 & - & - & 0,0013 & 0,0018 & - & - & $-0,0011$ & 0,0034 & - & - & $-0,0033$ & $-0,0058$ \\
\hline D05 & - & - & $-0,0106$ & $-0,0092$ & - & - & $-0,0153$ & $-0,0060$ & - & - & $-0,0279$ & $-0,0417$ \\
\hline PIM & & & & & $-0,0010 * *$ & $-0,0005$ & $-0,0009^{*}$ & $-0,0006$ & - & - & - & - \\
\hline $\mathrm{PA}$ & - & - & - & - & - & - & - & - & 0,0026 & 0,0023 & 0,0031 & 0,0040 \\
\hline PM & - & - & - & - & - & - & - & - & 0,0007 & 0,0008 & 0,0011 & 0,0012 \\
\hline PCONST & - & - & - & - & - & - & - & - & $0,0050 *$ & 0,0047 & 0,0057 & $0,0069 *$ \\
\hline PCRH & - & - & - & - & - & - & - & - & $0,0056^{* * * *}$ & $0,0055^{* *}$ & $0,0044^{*}$ & 0,0042 \\
\hline PSERV & - & - & - & - & - & - & - & - & $-0,0006$ & $-0,0007$ & 0,0001 & 0,0007 \\
\hline LN(INV) & - & - & - & - & - & - & - & - & $0,0200^{*}$ & $0,019^{*}$ & $0,0219^{* *}$ & $0,0249 * *$ \\
\hline $\mathrm{CA}$ & - & - & - & - & 0,0005 & 0,0005 & 0,0005 & 0,0005 & 0,0006 & 0,0006 & 0,0005 & 0,0005 \\
\hline AEB & - & - & - & - & - & - & - & - & 0,0022 & 0,0017 & 0,0020 & 0,0030 \\
\hline AES & - & - & - & - & - & - & - & - & $-0,0010$ & $-0,0010$ & 0,0001 & 0,0007 \\
\hline PCES & - & - & - & - & 0,0006 & 0,0001 & 0,0016 & 0,0005 & 0,0020 & 0,0019 & 0,0016 & 0,0016 \\
\hline$\overline{P U}$ & - & - & - & - & $-0,0001$ & $-0,0003$ & $-0,0004$ & $-0,0003$ & $-0,0004$ & $-0,0004$ & $-0,0003$ & $-0,0002$ \\
\hline $\mathrm{EP}$ & - & - & - & - & - & - & - & - & 0,0036 & 0,0046 & 0,0043 & 0,0025 \\
\hline PCS & - & - & - & - & - & - & - & - & $-0,0009$ & $-0,0009$ & $-0,0004$ & $-0,0003$ \\
\hline TO & - & - & - & - & - & - & - & - & $-0,0008$ & $-0,0010$ & $-0,0013$ & $-0,0010$ \\
\hline TD & - & - & - & - & $0,0039^{*}$ & $0,0043^{* * *}$ & 0,0032 & $0,0040^{*}$ & 0,0044 & 0,0044 & 0,0031 & 0,0024 \\
\hline$\beta \quad$ (Intercepto) & $\overline{0,0171^{* * * *}}$ & $13,5452 * * *$ & 0,0019 & $13,2247^{* *}$ & 0,1422 & $11,7306^{* *}$ & 0,1855 & $10,7808^{* *}$ & $-0,7559$ & 2,2824 & 0,0004 & -7.2859 \\
\hline $\mathbf{N}^{\circ}$ observaciones & 52 & 52 & 52 & 52 & 52 & 52 & 52 & 52 & 52 & 52 & 52 & 52 \\
\hline R Cuadrado & 0,1562 & 0,2560 & 0,1817 & 0,2764 & 0,3197 & 0,3741 & 0.3458 & 0,3852 & 0,5767 & 0,5782 & 0,5923 & 0,5963 \\
\hline Significancia global - p-valor & 0,0028 & 0,0000 & 0,0084 & 0,0001 & 0,0007 & 0,0000 & 0,0022 & 0,0012 & 0,0003 & 0,0005 & 0,0005 & 0,0007 \\
\hline
\end{tabular}

Nota 1: Las estimaciones presentan significancia de: $1 \%\left(^{* * *}\right), 5 \%\left(^{* *}\right)$ y $10 \%\left(\left(^{*}\right)\right.$.

Nota 2: los resultados de las estimaciones son robustos para evitar problemas de heterocedasticidad.

Fuente: Elaboración propia con base en DANE (2017a). 
Anexo 3.

Estimaciones de primera diferencia sobre el coeficiente de Gini 2002-2005

\begin{tabular}{|c|c|c|c|c|c|c|c|c|c|c|c|c|}
\hline \multirow[b]{2}{*}{$\begin{array}{c}\text { Variables independientes } \\
\text { Regresiones } \\
\end{array}$} & \multicolumn{4}{|c|}{ 1a especificación } & \multicolumn{4}{|c|}{ 2a especificación } & \multicolumn{4}{|c|}{$3^{\text {a }}$ especificación } \\
\hline & $\begin{array}{l}\text { RLS } \\
\text { (1) } \\
\end{array}$ & $\begin{array}{r}\text { RLS2 } \\
\text { (2) } \\
\end{array}$ & $\begin{array}{l}\text { RLS } \\
\text { dummy } \\
\text { año } \\
(3) \\
\end{array}$ & $\begin{array}{c}\text { RLS } 2 \\
\text { dummy } \\
\text { año } \\
(4) \\
\end{array}$ & $\begin{array}{l}\text { RLM X' } \\
\text { (5) }\end{array}$ & $\begin{array}{c}\text { RLM X' } 2 \\
(6) \\
\end{array}$ & $\begin{array}{c}\text { RLM } X^{\prime} \\
\text { dummy } \\
\text { años } \\
(7) \\
\end{array}$ & $\begin{array}{l}\text { RLM X' } 2 \\
\text { dummy } \\
\text { años } \\
(8) \\
\end{array}$ & RLM $\mathbf{X}^{\prime}$ & RLM X' 2 & $\begin{array}{c}\text { RLM X' } \\
\text { dummy } \\
\text { años } \\
(11) \\
\end{array}$ & $\begin{array}{l}\text { RLM X' } 2 \\
\text { dummy } \\
\text { años } \\
(12) \\
\end{array}$ \\
\hline LN(IPCFD) & $-0,0833$ & $-2,994$ & $-0,0463$ & $-2,5825$ & $-0,0710$ & $-3,6507$ & $-0,0103$ & $-2,7500$ & $-0,0253$ & $-1,7609$ & $-0,0049$ & 0,6755 \\
\hline LN(IPCFD) CUADRADO & - & 0,1133 & - & 0,0986 & - & 0,1388 & - & 0,1057 & - & 0,0669 & - & $-0,0262$ \\
\hline D04 & - & - & 0,0079 & 0,0050 & - & - & 0,0072 & 0,0033 & - & - & 0,0232 & 0,0249 \\
\hline D05 & - & - & $-0,0043$ & $-0,0057$ & - & - & $-0,0091$ & $-0,0094$ & - & - & 0,0070 & 0,0056 \\
\hline PIM & - & - & - & - & $-0,0035$ & $-0,0022$ & $-0,0048$ & $-0,0036$ & - & - & - & - \\
\hline$\overline{\mathrm{PA}}$ & - & - & - & - & - & - & - & - & 0,0094 & 0,0084 & 0,0114 & 0,0120 \\
\hline PM & - & - & - & - & - & - & - & - & $-0,0013$ & $-0,0027$ & $-0,0012$ & $-0,0006$ \\
\hline PCONST & - & - & - & - & - & - & - & - & 0,0097 & 0,0094 & 0,0112 & 0,0114 \\
\hline PCRH & - & - & - & - & - & - & - & - & $0,0186^{*}$ & 0,0160 & 0,0154 & 0,0163 \\
\hline PSERV & - & - & - & - & - & - & - & - & 0,0060 & 0,0055 & 0,0067 & 0,0070 \\
\hline LN(INV) & - & - & - & - & - & - & - & - & 0,0022 & 0,0029 & 0,0119 & 0,0125 \\
\hline $\mathrm{CA}$ & - & - & - & - & 0,0000 & 0,0002 & $-0,0002$ & 0,0000 & $-0,0009$ & $-0,0008$ & $-0,0009$ & $-0,0009$ \\
\hline$\overline{\mathrm{AEB}}$ & - & - & - & - & - & - & - & - & 0,0054 & 0,0057 & 0,0063 & 0,0063 \\
\hline AES & - & - & - & - & - & - & - & - & $-0,0018$ & $-0,0019$ & $-0,0015$ & $-0,0014$ \\
\hline PCES & - & - & - & - & 0,0010 & 0,0009 & 0,0012 & 0,0013 & 0,0022 & 0,0021 & 0,0012 & 0,0012 \\
\hline$\overline{P U}$ & - & - & - & - & $-0,0003$ & $-0,0001$ & $-0,0003$ & $-0,0001$ & 0,0012 & 0,0014 & 0,0009 & 0,0009 \\
\hline EP & - & - & - & - & - & - & - & - & 0,0034 & 0,0007 & 0,0025 & 0,0037 \\
\hline PCS & - & - & - & - & - & - & - & - & 0,0009 & 0,0009 & 0,0009 & 0,0009 \\
\hline TO & - & - & - & - & - & - & - & - & 0,0059 & 0,0055 & 0,0081 & 0,0083 \\
\hline TD & - & - & - & - & 0,0034 & 0,0043 & 0,0027 & 0,0035 & 0,0057 & 0,0052 & 0,0078 & 0,0081 \\
\hline $\begin{array}{ll}\beta & (\text { Intercepto })\end{array}$ & $-0,0002$ & $-0,0001$ & $-0,0024$ & $-0,0008$ & 0,0008 & 0,0015 & $-0,0006$ & 0,0014 & 0,0047 & 0,0044 & $-0,0051$ & $-0,0059$ \\
\hline $\mathrm{N}^{\circ}$ observaciones & 39 & 39 & 39 & 39 & 39 & 39 & 39 & 39 & 39 & 39 & 39 & 39 \\
\hline R Cuadrado & 0,0243 & 0,0470 & 0,0480 & 0,0636 & 0,0831 & 0,2844 & 0,1175 & 0,1305 & 0,4344 & 0,4387 & 0,4808 & 0,4813 \\
\hline Significancia global - p-valor & 0,4177 & 0,5693 & 0,7258 & 0,7815 & 0,7969 & 0,0409 & 0,9090 & 0,7937 & 0,1627 & 0,2251 & 0,0780 & 0,1157 \\
\hline
\end{tabular}

Nota 1: Las estimaciones presentan significancia de: $1 \%\left(^{* * *}\right), 5 \%\left(^{* *}\right)$ y $10 \%\left({ }^{*}\right)$.

Nota 2: los resultados de las estimaciones son robustos para evitar problemas de heterocedasticidad.

Fuente: Elaboración propia con base en DANE (2017a). 
Anexo 4.

Estimaciones de efectos fijos con datos panel sobre el coeficiente de Gini 2002-2005

\begin{tabular}{|c|c|c|c|c|c|c|}
\hline \multirow[b]{2}{*}{$\begin{array}{c}\text { Variables independientes } \\
\text { Regresiones } \\
\end{array}$} & \multicolumn{3}{|c|}{ 1a especificación } & \multicolumn{3}{|c|}{ 2a especificación } \\
\hline & $\begin{array}{c}\text { Efectos fijos } \mathrm{X}^{\prime} \\
(1)\end{array}$ & $\begin{array}{c}\text { Efectos fijos } X^{\prime} 2 \\
(2) \\
\end{array}$ & $\begin{array}{c}\text { Efectos fijos } X^{\prime} \\
\text { LN(IPCFD) año } \\
\text { (3) }\end{array}$ & $\begin{array}{c}\text { Efectos fijos } X^{\prime} \\
\text { (4) } \\
\end{array}$ & $\begin{array}{c}\text { Efectos fijos } X \\
\text { (5) }\end{array}$ & $\begin{array}{c}\text { Efectos fijos } X^{\prime} \\
\text { LN(IPCFD) año } \\
\text { (6) }\end{array}$ \\
\hline $\mathrm{LN}(\mathrm{IPCFD})$ & $-0,0605$ & $-2,7519$ & - & $-0,1128$ & $-4,6741$ & - \\
\hline LN(IPCFD) CUADRADO & - & 0,1049 & - & - & 0,1768 & - \\
\hline LN(IPCFD) 03 & - & - & 0,0000 & - & - & $-0,0004$ \\
\hline LN(IPCFD) 04 & - & - & 0,0007 & - & - & 0,0006 \\
\hline LN(IPCFD) 05 & - & - & 0,0002 & - & - & 0,0000 \\
\hline PIM & $-0,0034$ & $-0,0028$ & $-0,0042$ & - & - & - \\
\hline PA & - & - & - & 0,0088 & 0,0063 & $0,0113^{*}$ \\
\hline PM & - & - & - & $-0,0014$ & $-0,0050$ & 0,0010 \\
\hline PCONST & - & - & - & $0,0113^{* * *}$ & $0,0118 * * *$ & $0,0117 * *$ \\
\hline PCRH & - & - & - & $0,0148 *$ & 0,0076 & 0,0145 \\
\hline PSERV & - & - & - & $0,0052^{*}$ & $0,0047^{*}$ & 0,0066 \\
\hline LN(INV) & - & - & - & $-0,0056$ & $-0,0005$ & 0,0050 \\
\hline $\mathrm{CA}$ & 0,0000 & 0,0001 & $-0,0002$ & $-0,0008$ & $-0,0008$ & $-0,0009$ \\
\hline AEB & - & - & - & 0,0056 & $0,0064 *$ & 0,0055 \\
\hline $\mathrm{AES}$ & - & - & - & $-0,0010$ & $-0,0017$ & $-0,0006$ \\
\hline PCES & 0,0000 & 0,0005 & $-0,0005$ & 0,0014 & 0,0018 & 0,0014 \\
\hline $\mathrm{PU}$ & 0,0004 & 0,0003 & 0,0001 & 0,0026 & $0,0027^{*}$ & 0,0015 \\
\hline EP & - & - & - & $-0,0052$ & $-0,0155$ & $-0,0026$ \\
\hline PCS & - & - & - & 0,0009 & 0,0012 & 0,0005 \\
\hline TO & - & - & - & 0,0030 & 0,0017 & 0,0044 \\
\hline TD & 0,0009 & 0,0023 & 0,0019 & 0,0013 & $-0,0003$ & 0,0048 \\
\hline$\beta$ (Intercepto) & 1,3072 & 18,5314 & $0,5533 * * *$ & 0,6487 & 3,0478 & $-10,6090$ \\
\hline Sigma_u & 0,0439 & 0,0363 & 0,0412 & 0,0693 & 0,0784 & 0,0707 \\
\hline Sigma_e & 0,0204 & 0,0204 & 0,0208 & 0,0199 & 0,0196 & 0,0208 \\
\hline $\mathrm{N}^{\circ}$ observaciones & 52 & 52 & 52 & 52 & 52 & 52 \\
\hline R Cuadrado & 0,012 & 0,0380 & 0,0212 & 0,1116 & 0,1633 & 0,2054 \\
\hline Significancia global - p-valor & 0,8381 & 0,8109 & 0,8426 & - & - & - \\
\hline
\end{tabular}

Nota 1: Las estimaciones presentan significancia de: $1 \%\left(^{* * *}\right), 5 \%\left(^{* *}\right)$ y $10 \%\left(^{*}\right)$.

Nota 2: los resultados de las estimaciones son robustos para evitar problemas de heterocedasticidad.

Fuente: Elaboración propia con base en DANE (2017a). 
Anexo 5.

Estimaciones de efectos aleatorios con datos panel sobre el coeficiente de Gini 2002-2005

\begin{tabular}{|c|c|c|c|c|c|c|}
\hline \multirow{4}{*}{$\begin{array}{c}\text { Variables independientes } \\
\text { Regresiones } \\
\end{array}$} & \multicolumn{3}{|c|}{$1^{\text {a }}$ especificación } & \multicolumn{3}{|c|}{$2^{\mathrm{a}}$ especificación } \\
\hline & \multicolumn{3}{|c|}{ 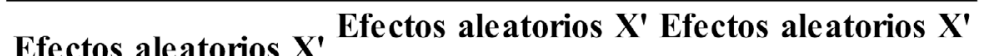 } & \multirow{3}{*}{$\begin{array}{c}\text { Efectos ale atorios } X^{\prime} \\
\text { (4) }\end{array}$} & \multirow{3}{*}{$\begin{array}{c}\text { Efectos aleatorios } X \\
\text { (5) } \\
\end{array}$} & \multirow{3}{*}{$\begin{array}{c}\text { Efectos aleatorios } X \\
\text { LN(IPCFD) año } \\
(6) \\
\end{array}$} \\
\hline & Efectos aleatonos $X$ & 2 & LN(IPCFD) año & & & \\
\hline & (1) & (2) & (3) & & & \\
\hline $\mathrm{LN}(\mathrm{IPCFD})$ & 0,0178 & $-2,2955 * *$ & - & 0,0649 & $-0,3966$ & - \\
\hline LN(IPCFD) CUADRADO & - & $0,0895 * *$ & - & - & 0,0177 & - \\
\hline LN(IPCFD) 03 & - & - & $-0,0002$ & - & - & $-0,0008$ \\
\hline LN(IPCFD) 04 & - & - & 0,0002 & - & - & $-0,0005$ \\
\hline $\mathrm{LN}(\mathrm{IPCFD}) 05$ & - & - & $-0,0006$ & - & - & $-0,0026 * *$ \\
\hline PIM & $-0,0011$ & $-0,0006$ & $-0,0011$ & - & - & - \\
\hline PA & - & - & - & 0,0026 & 0,0024 & 0,0027 \\
\hline $\mathrm{PM}$ & - & - & - & 0,0008 & 0,0008 & 0,0016 \\
\hline PCONST & - & - & - & $0,0050^{*}$ & $0,0047^{*}$ & $0,0062^{*}$ \\
\hline PCRH & - & - & - & $0,0056 * * *$ & $0,0055^{* *}$ & $0,0038^{*}$ \\
\hline PSERV & - & - & - & $-0,0006$ & $-0,0007$ & 0,0006 \\
\hline LN(INV) & - & - & - & $0,0200^{*}$ & 0,0191 & $0,0219^{*}$ \\
\hline $\mathrm{CA}$ & 0,0003 & 0,0003 & 0,0003 & 0,0007 & 0,0007 & 0,0006 \\
\hline$\overline{\mathrm{AEB}}$ & - & - & - & 0,0022 & 0,0018 & 0,0018 \\
\hline AES & - & - & - & $-0,0011$ & $-0,0011$ & 0,0004 \\
\hline PCES & $-0,0001$ & 0,0002 & 0,0006 & 0,0020 & 0,0020 & 0,0017 \\
\hline PU & 0,0003 & 0,0001 & 0,0005 & $-0,0005$ & $-0,0004$ & 0,0000 \\
\hline EP & - & - & - & 0,0037 & 0,0046 & 0,0066 \\
\hline PCS & - & - & - & $-0,0010$ & $-0,0009^{*}$ & 0,0000 \\
\hline $\mathrm{TO}_{0}$ & - & - & - & $-0,0009$ & $-0,0011$ & $-0,0008$ \\
\hline TD & 0,0031 & 0,0037 & 0,0027 & 0,0045 & 0,0044 & 0,0032 \\
\hline $\begin{array}{ll}\beta & \text { (Intercepto) }\end{array}$ & 0,2357 & $15,1669 * *$ & $0,4522 * * *$ & $-0,7559 *$ & 22,8243 & $-0,1390$ \\
\hline Sigma_u & 0,0206 & 0,0228 & 0,0198 & 0,0000 & 0,0000 & 0,0000 \\
\hline Sigma_e & 0,0204 & 0,0204 & 0,0208 & 0,0199 & 0,0196 & 0,0208 \\
\hline $\mathrm{N}^{\circ}$ observaciones & 52 & 52 & 52 & 52 & 52 & 52 \\
\hline R Cuadrado & 0,2955 & 0,3496 & 0,2975 & 0,5767 & 0,5782 & 0,5836 \\
\hline Significancia global - p-valor & 0,0000 & 0,0436 & 0,0000 & - & - & - \\
\hline
\end{tabular}

Nota 1: Las estimaciones presentan significancia de: $1 \%\left(^{* * *}, 5 \%(* *)\right.$ y $10 \%\left(^{*}\right)$.

Nota 2: los resultados de las estimaciones son robustos para evitar problemas de heterocedasticidad.

Fuente: Elaboración propia con base en DANE (2017a). 
Anexo 6.

Efectos fijos sobre el indice de Theil por departamento 2002-2005

\begin{tabular}{|c|c|c|c|c|c|c|}
\hline \multirow[b]{2}{*}{$\begin{array}{c}\text { Variables independientes } \\
\text { Regresiones }\end{array}$} & \multicolumn{3}{|c|}{$1^{a}$ especificación } & \multicolumn{3}{|c|}{ 2a especificación } \\
\hline & $\begin{array}{c}\text { Efectos fijos } \\
\mathrm{X}^{\prime} \\
(1)\end{array}$ & $\begin{array}{c}\text { Efectos fijos } \\
X^{\prime} 2 \\
(2)\end{array}$ & $\begin{array}{c}\text { Efectos fijos } X^{\prime} \\
\text { LN(IPCFD) año } \\
\text { (3) }\end{array}$ & $\begin{array}{c}\text { Efectos fijos } \\
X^{\prime} \\
(4)\end{array}$ & $\begin{array}{c}\text { Efectos fijos } X \\
\text { (5) }\end{array}$ & $\begin{array}{c}\text { Efectos fijos X' } \\
\text { LN(IPCFD) año } \\
(6)\end{array}$ \\
\hline LN(IPCFD) & $-0,2045$ & $-4,2482$ & - & $-0,3517^{*}$ & $-8,8267$ & - \\
\hline LN(IPCFD) CUADRADO & - & 0,1576 & - & - & 0,3285 & - \\
\hline LN(IPCFD) 03 & - & - & 0,0000 & - & - & $-0,0004$ \\
\hline LN(IPCFD) 04 & - & - & 0,0021 & - & - & 0,0024 \\
\hline LN(IPCFD) 05 & - & - & 0,0006 & - & - & 0,0031 \\
\hline PIM & $-0,0056$ & $-0,0046$ & $-0,0080$ & - & - & - \\
\hline $\mathrm{PA}$ & - & - & - & 0,0171 & 0,0125 & 0,0227 \\
\hline PM & - & - & - & $-0,0035$ & $-0,0103$ & 0,0030 \\
\hline PCONST & - & - & - & $0,0238 * * *$ & $0,0248 * * *$ & $0,0237 * *$ \\
\hline PCRH & - & - & - & $0,0353 * *$ & 0,0219 & 0,0343 \\
\hline PSERV & - & - & - & $0,0094 *$ & $0,0083 *$ & 0,0117 \\
\hline LN(INV) & - & - & - & $-0,0180$ & $-0,0084$ & 0,0056 \\
\hline $\mathrm{CA}$ & $-0,0001$ & 0,0000 & $-0,0007$ & $-0,0020$ & $-0,0020^{*}$ & $-0,0025$ \\
\hline$\overline{\mathrm{AEB}}$ & - & - & - & 0,0159 & $0,0175^{*}$ & 0,0144 \\
\hline $\mathrm{AES}$ & - & - & - & $-0,0031$ & $-0,0042$ & $-0,0035$ \\
\hline PCES & 0,0006 & 0,0014 & $-0,0008$ & 0,0034 & 0,0042 & 0,0032 \\
\hline$\overline{\mathrm{PU}}$ & 0,0001 & $-0,0001$ & $-0,0008$ & 0,0052 & 0,0055 & 0,0021 \\
\hline EP & - & - & - & $-0,0175$ & $-0,0366$ & $-0,0107$ \\
\hline PCS & - & - & - & 0,0033 & 0,0039 & 0,0015 \\
\hline TO & - & - & - & $0,0105^{*}$ & 0,0082 & $0,0150^{*}$ \\
\hline $\mathrm{TD}$ & 0,0009 & 0,0029 & 0,0039 & 0,0037 & 0,0008 & 0,0156 \\
\hline $\begin{array}{ll}\beta & \text { (Intercepto) }\end{array}$ & 3,230466 & 29,1096 & $0,6829 * *$ & 1,8732 & 57,2988 & $-3,0680$ \\
\hline Sigma_u & 0,1154 & 0,1018 & 0,0966 & 0,1616 & 0,2429 & 0,1632 \\
\hline Sigma_e & 0,0519 & 0,0524 & 0,0528 & 0,0508 & 0,0390 & 0,0534 \\
\hline $\mathrm{N}^{\circ}$ observaciones & 52 & 52 & 52 & 52 & 52 & 52 \\
\hline R Cuadrado & 0,0225 & 0,0049 & 0,0072 & 0,0604 & 0,1048 & 0,1271 \\
\hline Significancia global - p-valor & 0,5994 & 0,5993 & 0,4764 & - & - & - \\
\hline
\end{tabular}

Nota 1: Las estimaciones presentan significancia de: $1 \%\left(^{* * *}\right), 5 \%\left({ }^{* *}\right)$ y $10 \%\left(^{*}\right)$.

Nota 2: Los resultados de las estimaciones son robustos para evitar problemas de heterocedasticidad.

Fuente: Elaboración propia con base en DANE (2017a). 
Anexo 7.

Efectos fijos sobre el indice de Theil por departamento 2008-2016

\begin{tabular}{|c|c|c|c|c|c|c|}
\hline \multirow{3}{*}{ Variables independientes } & \multicolumn{3}{|c|}{$1^{a}$ especificación } & \multicolumn{3}{|c|}{ 2a especificación } \\
\hline & Efectos fijos & Efectos fijos $\mathrm{X}^{\prime}$ & Efectos fijos $X^{\prime}$ & Efectos fijos & Efectos fijos & Efectos fijos $\mathrm{X}^{\prime}$ \\
\hline & $X^{\prime}$ & 2 & LN(IPCFD) año & $\mathbf{X}^{\prime}$ & $\mathrm{x}$ & LN(IPCFD) año \\
\hline Regresiones & (1) & (2) & (3) & (4) & (5) & (6) \\
\hline LN(IPCFD) & $-0,0093$ & $-3,2477^{*}$ & - & $0,1956^{* * *}$ & $-2,5097$ & - \\
\hline LN(IPCFD) CUADRADO & - & $0,1260^{*}$ & - & - & 0,1048 & - \\
\hline LN(IPCFD) 09 & - & - & $-0,0007$ & - & - & 0,0007 \\
\hline LN(IPCFD) 10 & - & - & $-0,0010$ & - & - & 0,0012 \\
\hline LN(IPCFD) 11 & - & - & $-0,0030^{* * *}$ & - & - & 0,0000 \\
\hline LN(IPCFD) 12 & - & - & $-0,0035^{* *}$ & - & - & 0,0002 \\
\hline LN(IPCFD) 13 & - & - & $-0,0049 * * *$ & - & - & $-0,0004$ \\
\hline LN(IPCFD) 14 & - & - & $-0,0052 * *$ & - & - & 0,0001 \\
\hline LN(IPCFD) 15 & - & - & $-0,0072 * * *$ & - & - & $-0,0013$ \\
\hline LN(IPCFD) 16 & - & - & $-0,0082 * * *$ & - & - & $-0,0019$ \\
\hline PIM & 0,0032 & $0,0057^{*}$ & $-0,0021$ & - & - & \\
\hline PA & - & - & - & 0,0087 & 0,0057 & 0,0080 \\
\hline PM & - & - & - & 0,0028 & 0,0004 & 0,0022 \\
\hline PCONST & - & - & - & $-0,0018$ & $-0,0037$ & $-0,0016$ \\
\hline PCRH & - & - & - & $-0,0061$ & $-0,0114$ & $-0,0024$ \\
\hline PSERV & - & - & - & 0,0039 & 0,0025 & 0,0015 \\
\hline LN(INV) & - & - & - & $-0,0111$ & $-0,0155$ & $-0,0048$ \\
\hline $\mathrm{CA}$ & $-0,0002$ & $-0,0005$ & 0,0000 & $-0,0002$ & $-0,0004$ & $-0,0002$ \\
\hline $\mathrm{AEB}$ & - & - & - & $-0,0007$ & $-0,0007$ & 0,0002 \\
\hline AES & - & - & - & 0,0010 & 0,0002 & 0,0002 \\
\hline PCES & $-0,0110 * * *$ & $-0,0117 * * *$ & $-0,0002$ & $-0,0050$ & $-0,0051$ & 0,0005 \\
\hline $\begin{array}{l}\mathrm{PU} \\
\end{array}$ & $-0,0023$ & $-0,0028$ & $-0,0014$ & $-0,0021$ & $-0,0021$ & $-0,0015$ \\
\hline EP & - & - & - & $-0,0317 * *$ & $-0,0331 * *$ & $-0,0209$ \\
\hline PCS & - & - & - & $-0,0034 * *$ & $-0,0030^{*}$ & $-0,0032$ \\
\hline TO & - & - & - & $-0,0011$ & $-0,0011$ & 0,0003 \\
\hline TD & 0,0007 & 0,0001 & $-0,0014$ & $-0,0012$ & $-0,0016$ & $-0,0023$ \\
\hline $\begin{array}{ll}\beta & \text { (Intercepto) }\end{array}$ & 0,9412 & $21,7625^{*}$ & $0,7059 * * *$ & $-0,5839$ & 17,13472 & 13,92243 \\
\hline Sigma_u & 0,1007 & 0,1022 & 0,0627 & 0,1083 & 0,0998 & 0,1861 \\
\hline Sigma_e & 0,0443 & 0,0439 & 0,0414 & 0,0399 & 0,0396 & 0,0388 \\
\hline $\mathrm{N}^{\circ}$ observaciones & 216 & 216 & 216 & 216 & 216 & 216 \\
\hline R Cuadrado & 0,0264 & 0.0143 & 0.2817 & 0,1288 & 0,1376 & 0,1646 \\
\hline Significancia global - p-valor & 0,0000 & 0,0000 & 0,0000 & 0,0000 & 0,0000 & 0,0000 \\
\hline
\end{tabular}

Nota 1: Las estimaciones presentan significancia de: $\left.1 \%{ }^{(* *}\right), 5 \%\left(^{* *}\right)$ y $10 \%\left(\left(^{*}\right)\right.$.

Nota 2: Los resultados de las estimaciones son robustos para evitar problemas de heterocedasticidad.

Fuente: Elaboración propia con base en DANE (2017a). 
Anexo 8.

Efectos aleatorios sobre el indice de Theil por departamento 2002-2005

\begin{tabular}{|c|c|c|c|c|c|c|}
\hline \multirow[b]{2}{*}{$\begin{array}{c}\text { Variables independientes } \\
\text { Regresiones }\end{array}$} & \multicolumn{3}{|c|}{ 1ª especificación } & \multicolumn{3}{|c|}{ 2a especificación } \\
\hline & $\begin{array}{c}\text { Efectos aleatorios } \\
\mathrm{X}^{\prime} \\
(1) \\
\end{array}$ & $\begin{array}{c}\text { Efectos aleatorios } \\
X^{\prime} 2 \\
(2) \\
\end{array}$ & $\begin{array}{l}\text { Efectos ale atorios } \\
X^{\prime} \text { LN(IPCFD) año } \\
(3)\end{array}$ & $\begin{array}{c}\text { Efectos aleatorios } \\
\mathrm{X}^{\prime} \\
(4) \\
\end{array}$ & $\begin{array}{c}\text { Efectos aleatorios } \\
\mathbf{X} \\
(5) \\
\end{array}$ & $\begin{array}{c}\text { Efectos aleatorios } \\
X^{\prime} \text { LN(IPCFD) año } \\
(6)\end{array}$ \\
\hline LN(IPCFD) & 0,0488 & $-4,0007$ & - & 0,1394 & 0,2008 & - \\
\hline LN(IPCFD) CUADRADO & - & 0,1567 & - & - & $-0,0024$ & - \\
\hline $\mathrm{LN}(\mathrm{IPCFD}) 03$ & - & - & $-0,0005$ & - & - & $-0,0013$ \\
\hline LN(IPCFD) 04 & - & - & 0,0007 & - & - & $-0,0006$ \\
\hline LN(IPCFD) 05 & - & - & $-0,0018$ & - & - & $-0,0050$ \\
\hline PIM & $-0,0027 * *$ & $-0,0016$ & $-0,002 *$ & - & - & - \\
\hline $\mathrm{PA}$ & - & - & - & 0,0061 & 0,0061 & 0,0056 \\
\hline $\mathrm{PM}$ & - & - & - & 0,0022 & 0,0022 & 0,0039 \\
\hline PCONST & - & - & - & 0,0097 & 0,0097 & 0,0118 \\
\hline PCRH & - & - & - & $0,0145^{* * *}$ & $0,0146^{* *}$ & $0,0109 *$ \\
\hline PSERV & - & - & - & $-0,0005$ & $-0,0005$ & 0,0019 \\
\hline LN(INV) & - & - & - & 0,0456 & 0,0457 & 0,0503 \\
\hline $\mathrm{CA}$ & 0,0009 & 0,0008 & 0,0008 & 0,0015 & 0,0015 & 0,0014 \\
\hline $\mathrm{AEB}$ & - & - & - & 0,0041 & 0,0041 & 0,0030 \\
\hline AES & - & - & - & $-0,0034$ & $-0,0034$ & $-0,0006$ \\
\hline PCES & $-0,0002$ & 0,0002 & 0,0019 & 0,0046 & 0,0046 & 0,0037 \\
\hline $\mathrm{PU}$ & 0,0004 & 0,0000 & 0,0008 & $-0,0012$ & $-0,0012$ & $-0,0003$ \\
\hline EP & - & - & - & 0,0124 & 0,0123 & 0,0181 \\
\hline PCS & - & - & - & $-0,0015$ & $-0,0015$ & 0,0006 \\
\hline TO & - & - & - & $-0,0039$ & $-0,0039$ & $-0,0036$ \\
\hline TD & 0,0067 & 0,0076 & 0,0054 & 0,0073 & 0,0073 & 0,0058 \\
\hline$\beta \quad$ (Intercepto) & $-0,1802$ & 25,9644 & $0,4142 * * *$ & $-2,2069 * * *$ & $-2,6109$ & $-0,8489$ \\
\hline Sigma_u & 0,0486 & 0,0543 & 0,0457 & 0 & 0,0000 & 0,0000 \\
\hline Sigma_e & 0,0519 & 0,0524 & 0,0528 & 0,0508 & 0,0509 & 0,0534 \\
\hline $\mathrm{N}^{\circ}$ observaciones & 52 & 52 & 52 & 52 & 52 & 52 \\
\hline R Cuadrado & 0,2871 & 0,2940 & 0,2933 & 0,5209 & 0,5209 & 0,5223 \\
\hline Significancia global - p-valor & 0,0000 & 0,0000 & 0,0000 & - & - & - \\
\hline
\end{tabular}

Nota 1: Las estimaciones presentan significancia de: $1 \%\left({ }^{* * *}\right), 5 \%\left(^{* *}\right)$ y $10 \%\left(^{(*)}\right.$.

Nota 2: Los resultados de las estimaciones son robustos para evitar problemas de heterocedasticidad.

Fuente: Elaboración propia con base en DANE (2017a). 
Anexo 9.

Efectos aleatorios sobre el indice de Theil por departamento 2008-2016

\begin{tabular}{|c|c|c|c|c|c|c|}
\hline \multirow[b]{2}{*}{ Variables inde pendientes } & \multicolumn{3}{|c|}{$1^{\text {a }}$ especificación } & \multicolumn{3}{|c|}{ 2a especificación } \\
\hline & $\begin{array}{c}\text { Efectos aleatorios } \\
\mathrm{X}^{\prime}\end{array}$ & $\begin{array}{l}\text { Efectos aleatorios } \\
\mathrm{X}^{\prime} 2\end{array}$ & $\begin{array}{l}\text { Efectos aleatorios } \\
X^{\prime} \text { LN(IPCFD) año }\end{array}$ & $\begin{array}{c}\text { Efectos aleatorios } \\
\mathrm{X}^{\prime}\end{array}$ & $\begin{array}{c}\text { Efectos aleatorios } \\
\qquad \mathrm{X}\end{array}$ & $\begin{array}{l}\text { Efectos aleatorios } \\
X^{\prime} \text { LN(IPCFD) año }\end{array}$ \\
\hline Regresiones & (1) & (2) & (3) & (4) & (5) & (6) \\
\hline $\mathrm{LN}(\mathrm{IPCFD})$ & $-0,0718$ & $-3,5963 * *$ & - & 0,1365 & $-2,2595^{*}$ & - \\
\hline LN(IPCFD) CUADRADO & - & $0,1363 * *$ & - & - & $0,0924^{*}$ & - \\
\hline $\mathrm{LN}(\mathrm{IPCFD}) 09$ & - & - & $-0,0007$ & - & - & $-0,0016$ \\
\hline LN(IPCFD) 10 & - & - & $-0,0012$ & - & - & $-0,0022$ \\
\hline LN(IPCFD) 11 & - & - & $-0,0033 * * *$ & - & - & $-0,0047 * *$ \\
\hline LN(IPCFD) 12 & - & - & $-0,0040^{* * * *}$ & - & - & $-0,0065^{* * *}$ \\
\hline LN(IPCFD) 13 & - & - & $-0,0056^{* * *}$ & - & - & $-0,0105^{* * *}$ \\
\hline LN(IPCFD) 14 & - & - &,$- 0062082 * * *$ & - & - & $-0,0117 * * *$ \\
\hline LN(IPCFD) 15 & - & - & $-0,0082 * * *$ & - & - & $-0,0136^{* * *}$ \\
\hline LN(IPCFD) 16 & - & - & $-0,0095 * * *$ & - & - & $-0,0149 * * *$ \\
\hline PIM & 0,0006 & 0,0012 & $-0,0028$ & - & - & - \\
\hline PA & - & - & - & $-0,0001$ & $-0,0007$ & $0,0049^{*}$ \\
\hline PM & - & - & - & $-0,0007$ & $-0,0014$ & $0,0061 * * *$ \\
\hline PCONST & - & - & - & $-0,0033$ & $-0,0039$ & $0,0111^{* * *}$ \\
\hline PCRH & - & - & - & $-0,0017$ & $-0,0029$ & $-0,0023$ \\
\hline PSERV & - & - & - & 0,0011 & 0,0001 & $0,0078^{* * *}$ \\
\hline LN(INV) & - & - & - & $-0,0137$ & $-0,0178$ & $0,0542 * *$ \\
\hline $\mathrm{CA}$ & 0,0003 & 0,0001 & 0,0001 & 0,0000 & $-0,0002$ & 0,0004 \\
\hline AEB & - & - & - & $-0,0007$ & $-0,0003$ & 0,0062 \\
\hline AES & - & - & - & 0,0019 & 0,0010 & 0,0006 \\
\hline PCES & $-0,0062 * *$ & $-0,0073 * * *$ & 0,0030 & $-0,0032$ & $-0,0036$ & $0,0084 * *$ \\
\hline PU & 0,0004 & $-0,0002$ & $-0,0022$ & $-0,0021$ & $-0,0021$ & $-0,0052 * * *$ \\
\hline EP & - & - & - & $-0,0226 * * *$ & $-0,0241 * * *$ & 0,0111 \\
\hline PCS & - & - & - & $-0,0038 * *$ & $-0,0033 * *$ & $-0,0020$ \\
\hline TO & - & - & - & $-0,0008$ & $-0,0007$ & $-0,0048^{*}$ \\
\hline TD & 0,0031 & 0,0018 & $-0,0009$ & 0,0008 & 0,0003 & 0,0017 \\
\hline $\begin{array}{ll}\beta & \text { (Intercepto) }\end{array}$ & $1,4767^{* *}$ & $24,31093^{* *}$ & $0,7110^{* * *}$ & 0,0851 & $15,7168^{*}$ & $-0,5940$ \\
\hline Sigma u & 0,0542 & 0,0559 & 0,0603 & 0,0540 & 0,0566 & 0,0000 \\
\hline Sigma_e & 0,0443 & 0,0439 & 0,0414 & 0,0399 & 0,0396 & 0,0407 \\
\hline $\mathrm{N}^{\circ}$ observaciones & 216 & 216 & 216 & 216 & 216 & 216 \\
\hline R Cuadrado & 0.0853 & 0.1472 & 0.1474 & 0.1732 & 0,1764 & 0,5582 \\
\hline Significancia global - p-valor & 0,0000 & 0,0000 & 0,0000 & 0,0000 & 0,0000 & 0,0000 \\
\hline
\end{tabular}

Nota 1: Las estimaciones presentan significancia de: $1 \%\left({ }^{* * *}\right), 5 \%\left(^{* *}\right)$ y $10 \%\left(^{*}\right)$.

Nota 2: los resultados de las estimaciones son robustos para evitar problemas de heterocedasticidad.

Fuente: Elaboración propia con base en DANE (2017a). 